\title{
Human occupation of the Arabian Empty Quarter during MIS 5: evidence from Mundafan Al-Buhayrah, Saudi Arabia
}

\author{
Huw S. Groucutt a, *, Tom S. White a , Laine Clark-Balzan ${ }^{a}$, Ash Parton ${ }^{\text {a }}$, Rémy Crassard ${ }^{\mathrm{b}}$, \\ Ceri Shipton ${ }^{\mathrm{c}}$, Richard P. Jennings ${ }^{\mathrm{a}}$, Adrian G. Parker ${ }^{\mathrm{d}}$, Paul S. Breeze ${ }^{\mathrm{e}}$, \\ Eleanor M.L. Scerri ${ }^{\mathrm{f}}$, Abdullah Alsharekh ${ }^{\mathrm{g}}$, Michael D. Petraglia ${ }^{\mathrm{a}}$ \\ ${ }^{a}$ Research Laboratory for Archaeology and the History of Art, University of Oxford, New Barnett House, 28 Little Clarendon Street, OX1 2HU, Oxford, UK \\ ${ }^{\mathrm{b}}$ CNRS, UMR 5133 'Archéorient', Maison de l'Orient et de la Méditerranée, 7 rue Raulin, 69007, Lyon, France \\ ' School of Social Science, University of Queensland, Brisbane QLD 4072, Australia \\ ${ }^{\mathrm{d}}$ Department of Social Sciences, Oxford Brookes University, Gibbs Building, Gipsy Lane, Oxford, OX3 OBP, UK \\ e Department of Geography, King's College London, Strand, London, WC2R 2LS, UK \\ ${ }^{\mathrm{f}}$ PACEA, Université Bordeaux 1, Bâtiment B19, Avenue des Facultés, 33405, Talence Cedex, France \\ ${ }^{g}$ Department of Archaeology, College of Tourism and Archaeology, King Saud University, Riyadh, Saudi Arabia
}

\section{A R T I C L E I N F O}

\section{Article history:}

Received 6 January 2015

Received in revised form

18 April 2015

Accepted 24 April 2015

Available online

\section{Keywords:}

Arabia

Pleistocene

Middle Palaeolithic

Empty Quarter

MIS 5

\begin{abstract}
A B S T R A C T
The Empty Quarter (or Rub' al Khali) of the Arabian Peninsula is the largest continuous sandy desert in the world. It has been known for several decades that Late Pleistocene and Holocene deposits, representing phases of wetter climate, are preserved there. These sequences have yielded palaeontological evidence in the form of a variety of vertebrate and invertebrate fossils and have been dated using various radiometric techniques. However, evidence for human presence during these wetter phases has until now been ephemeral. Here, we report on the first stratified and dated archaeology from the Empty Quarter, recovered from the site of Mundafan Al-Buhayrah (MDF-61). Human occupation at the site, represented by stone tools, has been dated to the later part of Marine Isotope Stage (MIS) 5 using multiple luminescence dating techniques (multigrain and single grain OSL, TT-OSL). The sequence consists primarily of lacustrine and palustrine sediments, from which evidence for changing local environmental conditions has been obtained through analysis of fossil assemblages (phytoliths and nonmarine molluscs and ostracods). The discovery of securely-dated archaeological material at $\sim 100$ to $80 \mathrm{ka}$ in the Empty Quarter has important implications for hypotheses concerning the timing and routes of dispersal of Homo sapiens out of Africa, which have been much debated. Consequently, the data presented here fill a crucial gap in palaeoenvironmental and archaeological understanding of the southern Arabian interior. Fossils of $\mathrm{H}$. sapiens in the Levant, also dated to MIS 5, together with Middle Palaeolithic archaeological sites in Arabia and India are thought to represent the earliest dispersal of our species out of Africa. We suggest that the widespread occurrence of similar lithic technologies across southern Asia, coupled with a growing body of evidence for environmental amelioration across the Saharo-Arabian belt, indicates that occupation of the Levant by $H$. sapiens during MIS 5 may not have been a brief, localized 'failed dispersal', but part of a wider demographic expansion.
\end{abstract}

(c) 2015 Elsevier Ltd. All rights reserved.

\section{Introduction}

In recent years the Arabian Peninsula has emerged as a critical region for research into low-latitude Quaternary environmental change and hominin demography (e.g. Petraglia and Rose, 2009;

\footnotetext{
* Corresponding author. Tel.: +44 1865275134.

E-mail address: huw.groucutt@rlaha.ox.ac.uk (H.S. Groucutt).
}

Groucutt and Petraglia, 2012). The Empty Quarter (or Rub' al Khali) is the largest sandy desert in the world, occupying 650,000 $\mathrm{km}^{2}$ of southern Arabia, but little is known of its Quaternary palaeoenvironmental and archaeological records. Although it has been suggested that expansions of human populations into and through the interior of Arabia are likely to have been closely linked to humid climatic phases (e.g. Vaks et al., 2007; Rosenberg et al., 2011a; Breeze et al., 2015; Jennings et al., 2015; Parton 
et al., 2015a, b), the complexity of the terrestrial Quaternary record in Arabia and its implications for understanding demography is still only just being appreciated.

Pleistocene deposits preserved in the Mundafan Basin (Najran Province, southern Saudi Arabia), on the south-western edge of the Empty Quarter, provide opportunities to examine the link between climatic and environmental change and human occupation of the region (Fig. 1). Early palaeoenvironmental studies (McClure, 1976, 1984) revealed that a large lake had been present at Mundafan, the evidence for which was obtained from inverted relief features preserved within the basin; these take the form of flat-topped benches and mounds of calcareous and fossiliferous marls, clays and silts. These initial reconstructions identified two main phases of lake formation and suggested that at its maximum extent the waterbody had attained a length of $\sim 150 \mathrm{~km}$ (McClure, 1976). Radiocarbon age estimates (McClure, 1976) placed the earlier lake phase in late Marine Isotope Stage (MIS) 3, between $~ 30$ and 21 thousand years ago $(\mathrm{ka})$ and the later phase between $\sim 9$ and $6 \mathrm{ka}$ (early Holocene). However, more recent OSL dating of the Mundafan palaeolake sediments has placed the earlier phases of lake formation within MIS 5c and 5a (Rosenberg et al., 2011a). Archaeological material from the Mundafan Basin is known from numerous surficial Middle Palaeolithic and Neolithic sites (cf. Crassard et al., 2013), although none of these have been associated with a securely dated sequence.

Here, we report on the newly discovered site of Mundafan AlBuhayrah (MDF-61), which has yielded the first stratified and dated archaeological material from the Empty Quarter. The application of multiple luminescence dating techniques has provided further evidence for lake formation within the Mundafan Basin during MIS 5, and importantly constrains the period of human occupation at MDF-61 to between 100 and $80 \mathrm{ka}$. A large assemblage of Middle Palaeolithic artefacts was recovered from both the stratified sediment sequence and from the immediately surrounding deflated desert surface. The assemblage is characterized by centripetal Levallois reduction and shares technological similarities with East African, Levantine and Indian assemblages dated to MIS 5. Detailed palaeoenvironmental analyses provide new insights into local ecological conditions within the Empty Quarter during this period.

\section{Site details and geological setting}

The Mundafan Basin occupies a topographical depression with an area of $\sim 363 \mathrm{~km}^{2}$, extending from $18.52 \mathrm{~N}, 45.42 \mathrm{E}$ in the southeast to $18.80 \mathrm{~N}, 45.13 \mathrm{E}$ in the northwest (Fig. 2). It is bounded to the east by the Tuwayq Escarpment; the longest and highest of several Jurassic limestone escarpments in central Saudi Arabia, which extends $\sim 1300 \mathrm{~km}$ from the Nefud Desert in the north to $\sim 60 \mathrm{~km}$ south of Mundafan. To the west and south, the depression is bounded by large linear dunes. The Mundafan Basin is a large deflationary basin, with complex geomorphology reflecting repeated shifts between arid and humid conditions. The floor of the basin is relatively flat, attaining $860-870 \mathrm{~m}$ above sea level. Pleistocene sediments are preserved within the basin as raised flattopped landforms, typically capped by heavily indurated calcretes that have served to protect the underlying and less durable sediments from erosion. In many cases, these landforms are associated with surface scatters of worked lithic material. The site of MDF-61 is one such feature, covering an area of $\sim 2.7 \mathrm{~km}^{2}$, consisting of a sequence of lacustrine marls, palustrine carbonates, calcareous silty-sands and aeolian sands preserved above the deflated basin floor and capped by an indurated calcrete (Fig. 3).

\section{Materials and methods}

A $2 \times 2 \mathrm{~m}$ trench was excavated at a high point in the MDF-61 sequence to a depth of $1.3 \mathrm{~m}$ (Fig. 4). Samples for palaeoenvironmental analysis were retrieved from this trench (Section A) to a depth of $1.3 \mathrm{~m}$ and from an adjacent section (Section B),

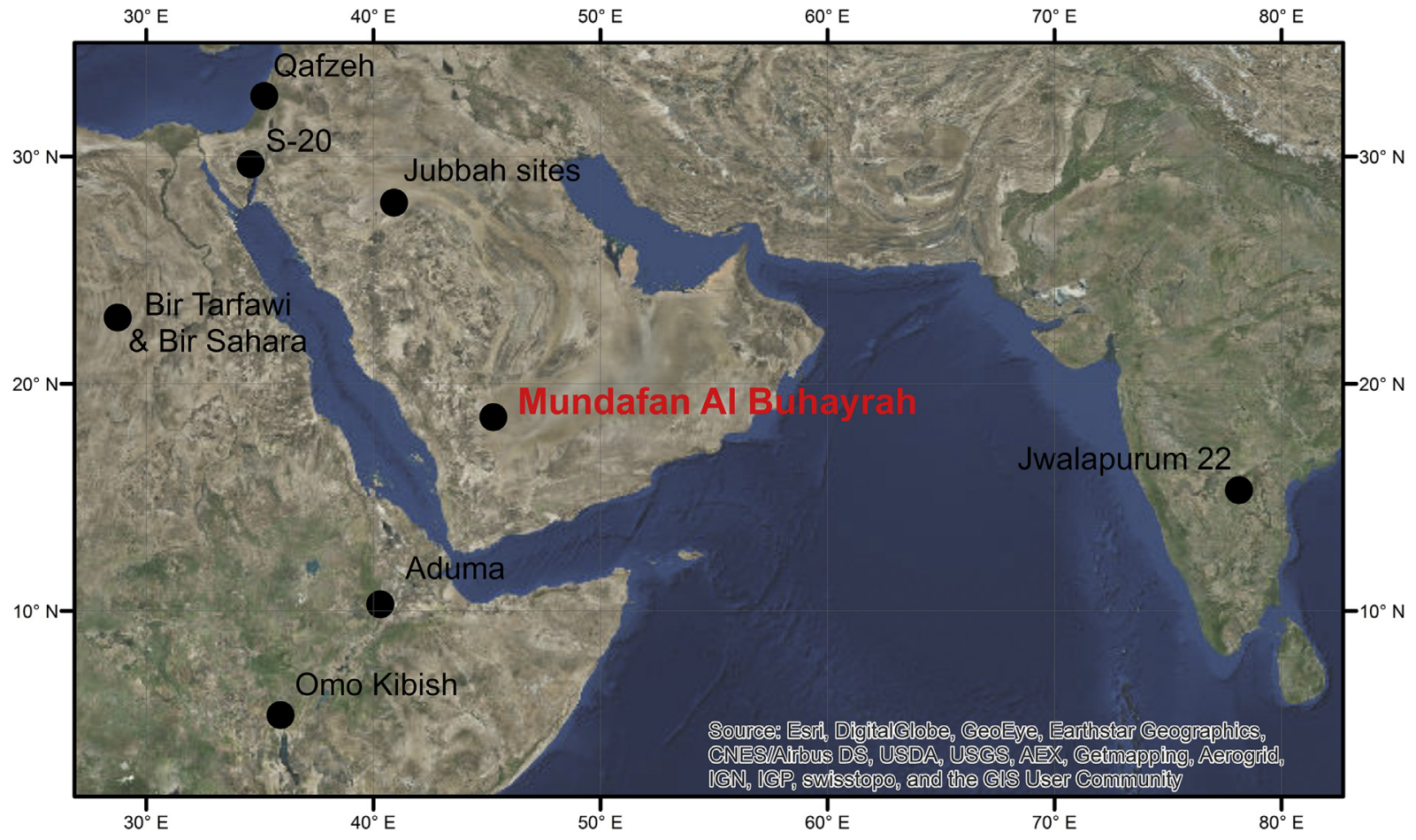

Fig. 1. The location of Mundafan Al Buhayrah (MDF-61), Najran Province, Saudi Arabia, relative to other key sites with similar lithic technology dated to mid-to late-MIS 5. 


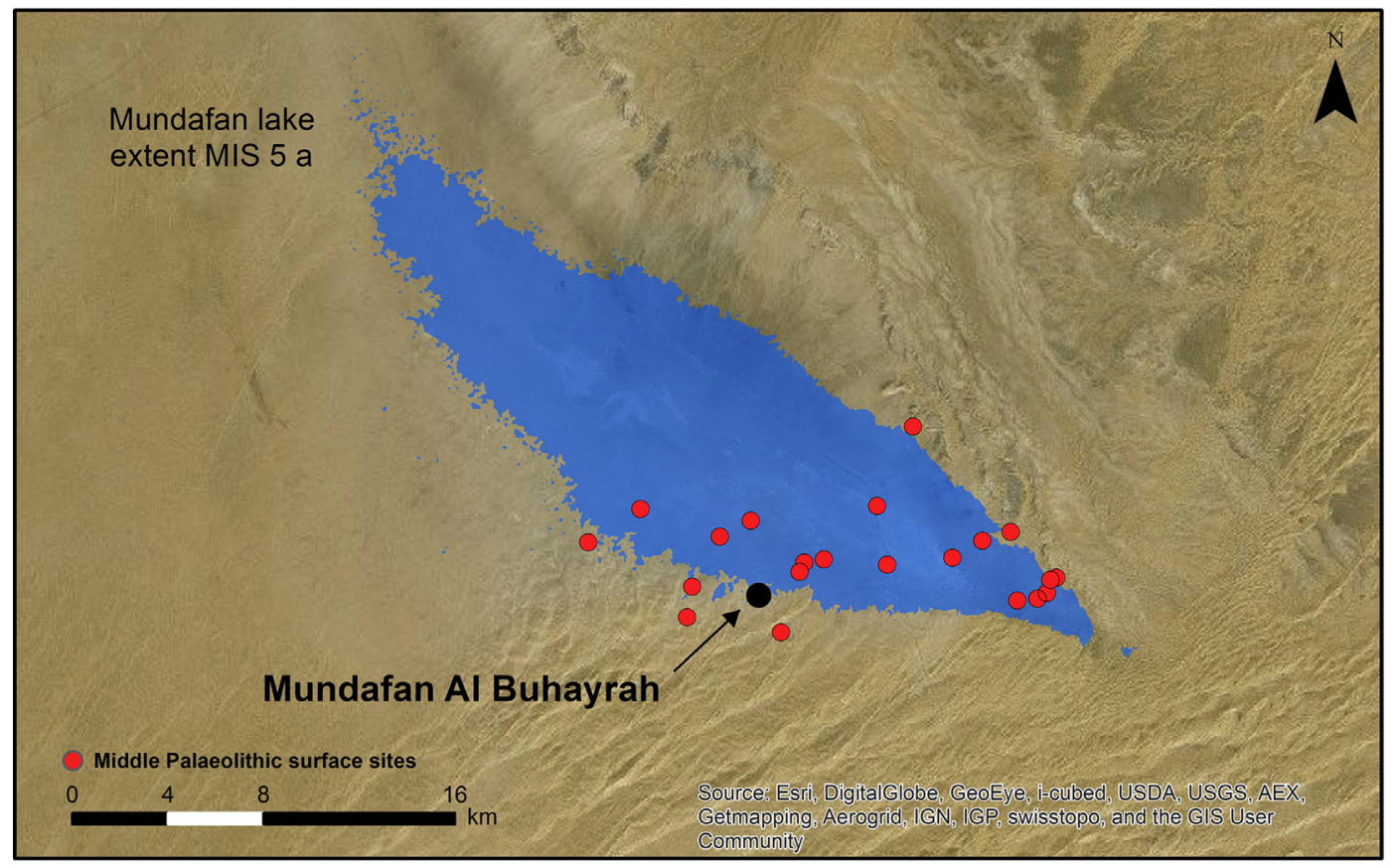

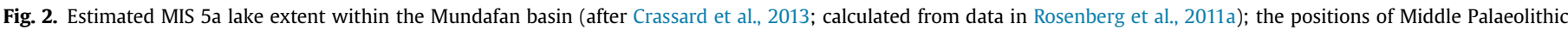
surface scatters discovered within the basin are also shown.

which exposed a further $1.2 \mathrm{~m}$ of Pleistocene sediments below the base of the archaeological trench. Sedimentary units could be traced between the base of the Section $A$ and the upper part of Section B, allowing contiguous sampling of the MDF-61 sequence to a total depth of $\sim 2.5 \mathrm{~m}$ (Fig. 5). Samples were retrieved at $5 \mathrm{~cm}$ intervals for various laboratory analyses. Loss on ignition analyses for organic carbon $\left(\mathrm{LOI}_{\mathrm{org}}\right.$ ) and carbonate $\left(\mathrm{LOI}_{\mathrm{carb}}\right)$ content were undertaken following the procedures outlined by Heiri et al. (2001), whilst magnetic susceptibility analysis followed Dearing (1999). In order to determine grain size, samples of air-dried sediment were gently disaggregated in de-ionised water and analysed using a Malvern Mastersizer 2000. Phytoliths from the archaeologybearing strata were prepared using the methodology outlined in Parker et al. (2011) and microscopic charcoal contained on the

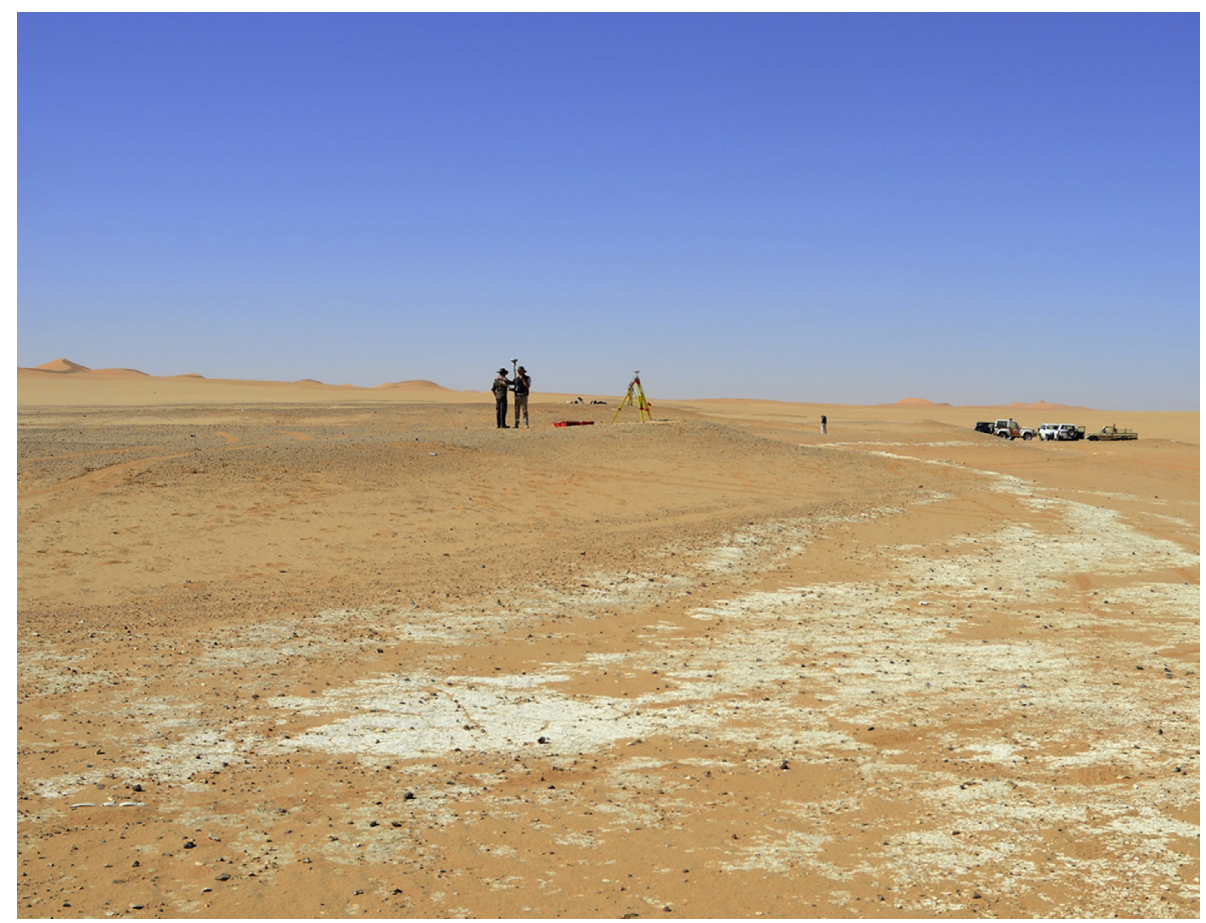

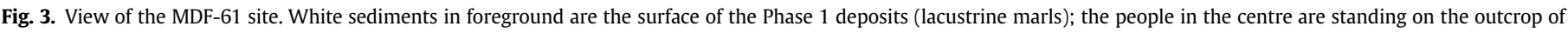
palustrine carbonates and calcareous silts (Phases 2 and 3). 


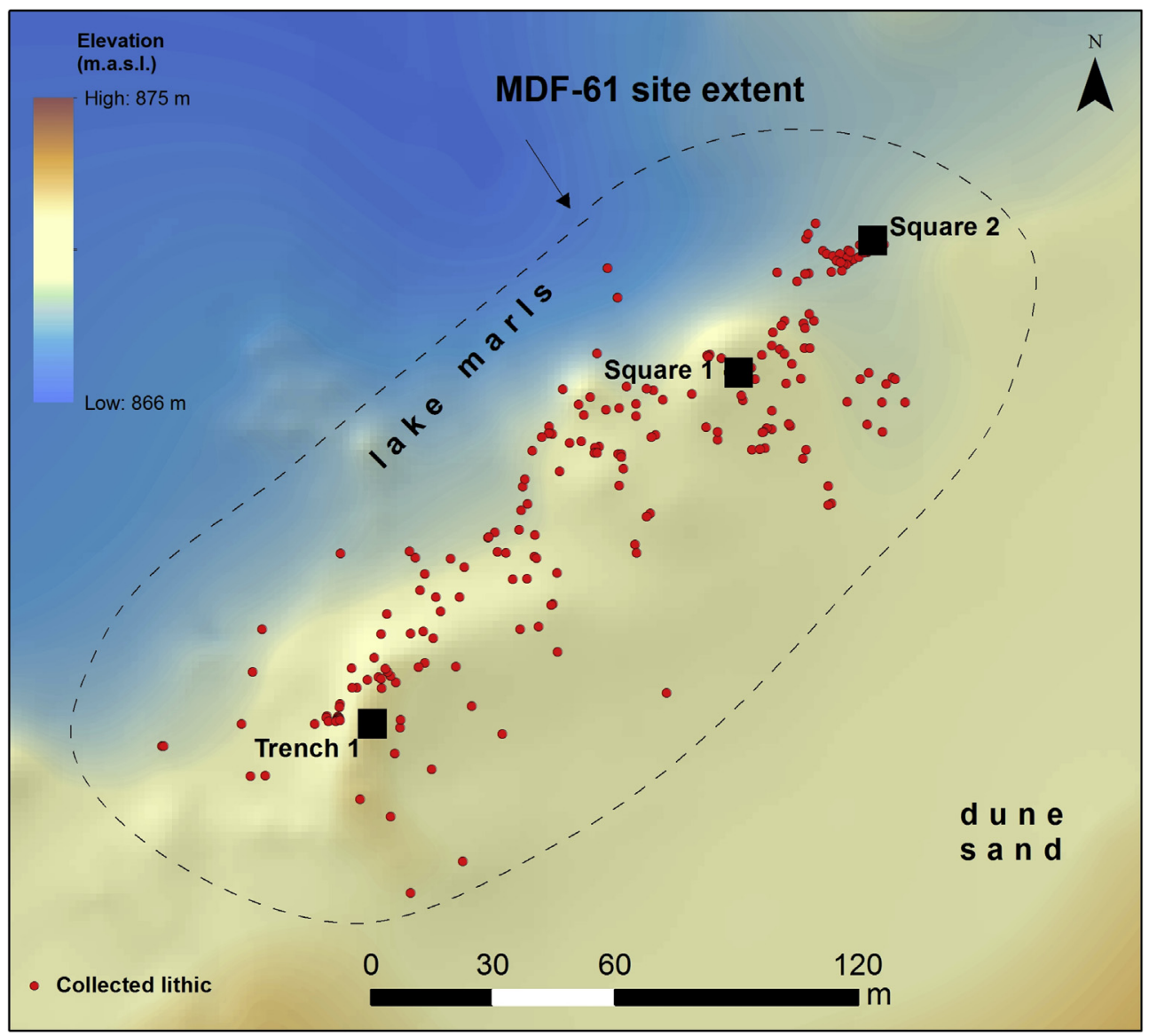

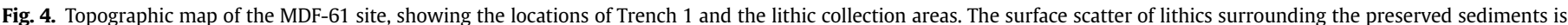
also shown.

phytolith slides was counted using the point estimation method (Clark, 1982). Sample residues that had been subjected to sedimentary analyses were subsequently examined under a lowpowered binocular microscope for extraction of non-marine molluscan and ostracod fossils. Finally, a variety of typological, technological and morphological characteristics were recorded for all recovered lithics, allowing us to characterize the MDF-61 lithic assemblage. Details of sampling for OSL dating are given below.

\section{Stratigraphy}

The sequence preserved at MDF-61 comprised 13 stratigraphic units that can be divided into three distinct phases of sedimentation (Fig. 5):

\subsection{Phase 1 - cemented sandy marls (Unit 1)}

The basal unit of the studied sequence was not bottomed, but $\sim 0.3 \mathrm{~m}$ of pale grey massive lacustrine marls were recorded at the base of Section B. This unit was also observed eroding out downslope of the excavated section as a shallow $(<0.25 \mathrm{~m})$ bed extending along the northeastern face of the sequence. These sediments contained no fossils or evidence for vegetation development.

\subsection{Phase 2 - palustrine carbonates (Units $2-8$ )}

The basal lacustrine sediments were overlain by $\sim 1.5 \mathrm{~m}$ of highly calcareous pale grey silty sands. Seven units were defined within the Phase 2 sequence on the basis of degree of cementation, abundance of comminuted shell debris and root voids and evidence for weathering. The uppermost units (7 and 8) were the most strongly cemented. Diffuse contacts between the Phase 2 units suggest that they represent a relatively continuous phase of sedimentation. Grain size characteristics indicate varying contributions of aeolian and water-lain sediments. Iron staining was common throughout, particularly within vertically pervasive root voids, plant impressions and desiccation cracks. Rhizoliths (up to $4 \mathrm{~cm}$ in length) and calcitic nodules (up to $2 \mathrm{~cm}$ in diameter) were present throughout Unit 7. Comminuted shell debris was present throughout this part of the sequence, with particularly high concentrations in Unit 5 $(170-140 \mathrm{~cm})$ and Unit $7(105-80 \mathrm{~cm})$.

\subsection{Phase 3 - calcareous silts (Units 9-12)}

The uppermost part of the sequence consisted of weakly cemented, highly calcareous silty sands, with root holes, rhizoliths and occasional calcitic nodules. The degree of cementation increased towards the top of the sequence. These units comprise the artefact-bearing stratigraphic layers, and were separated from the underlying unit by a sharp contact, reflecting a break and/or significant change in sedimentation. Fossils were absent from these sediments, although iron-stained root voids remained abundant. The uppermost unit consisted of a heavily weathered, indurated calcrete intermixed with red-brown aeolian sand, which has formed a partially developed desert pavement. The durability of 

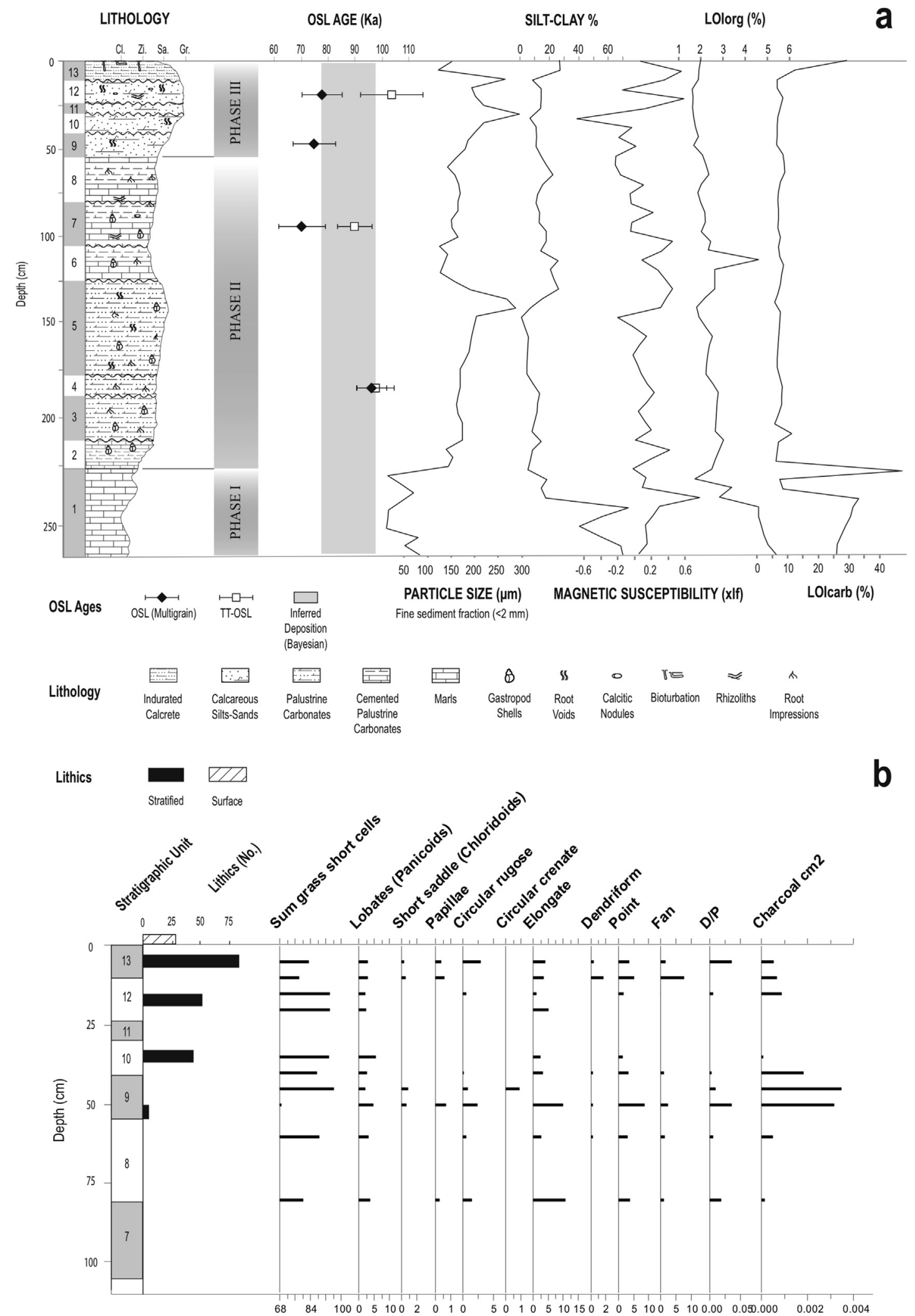

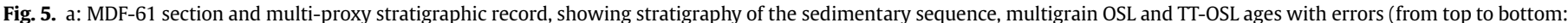

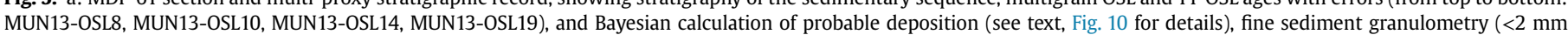

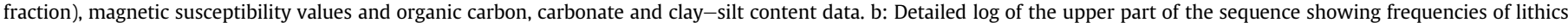
and relative abundance of phytoliths and charcoal. 
this calcrete has served to armour the underlying deposits, protecting them from erosion.

\section{Palaeoenvironmental and palaeoecological evidence}

\subsection{Sedimentological analyses}

Multiproxy sedimentological data (Fig. 5) generally showed greater variation at the base of the MDF-61 sequence, particularly within Units 1 and 2 . Phase 1 is represented by marls comprising poorly-sorted silts and very fine sands. A sharp increase in carbonate content marks the contact between Units 1 and 2 (and Phases 1 and 2), possibly due to the liberation of exposed carbonate material associated with the underlying Unit 1, although the precipitation of carbonates within the water body or near surface groundwater may have also occurred. The absence of pedogenic features suggests a continuous sedimentation cycle during this lacustrine phase. The lack of vertical gradation/maturation of the marls into the overlying palustrine carbonates indicates an abrupt change in sedimentation at the end of the lake phase. The Phase 2 deposits predominantly comprise palustrine carbonate sediments, which show an increase in particle size between Units 2 and 6 with a corresponding reduction carbonate values. An abrupt influx of well-sorted aeolian sand is evident in Unit $5(\sim 1.35 \mathrm{~m})$. The Phase 3 deposits show an overall increase in particle size, punctuated by influxes of coarser sand at the interfaces between Units 10-11 and $12-13$; there is also a sharp decline in magnetic susceptibility values at the transition between units 10 and 11 . This is followed by a sharp rise in magnetic susceptibility values as particle sizes decline (Fig. 5). Organic carbon content generally declines throughout units 9-12, before rising sharply within Unit 13. This pattern is also reflected in carbonate and clay/silt content values; all of these values display a degree of covariance throughout the sequence (Fig. 5).

\subsection{Phytoliths and charcoal}

Phytoliths were intermittently present within units 8-13 (Fig. 5). The lowermost assemblage, recovered from Unit 8 at a depth of $\sim 80 \mathrm{~cm}$, was dominated by phytoliths of short-bodied grasses and long-bodied elongates. Low frequencies of circular rugose phytoliths from dicotyledonous taxa were also present. Phytoliths were well preserved in Unit 9 and the lower part of Unit 10. Short-bodied grass cells dominated the spectra in this part of the sequence, accounting for up to $90 \%$ of the total. These were mainly round, small square and rectangular in form. Lobate morphotypes derived from tall mesic $\mathrm{C}_{4}$ panicoid grass formed $~ 5 \%$ of the total. In Unit 9, two samples contained low levels of $\mathrm{C}_{4}$ aridadapted chloridoid grasses ( $1 \%$ ). Low levels (up to $2 \%$ ) of circular rugose morphotypes were present in the lower part of Unit 9 with $\mathrm{D} / \mathrm{P}$ values peaking at values $\sim 0.03$. These are absent from the upper part of Unit 9 and from Unit 10 . Two circular crenate phytoliths were noted in the lower part of Unit 9. Phytoliths were absent from the upper part of Unit 10 and from Unit 11, corresponding with peak particle size values. Phytoliths are present again in Units 12 and 13 and again show a dominance of short-bodied grass morphotypes with low levels of Panicoids ( $5 \%$ ) throughout). Chloridoids appear in Unit 13 only, while charcoal levels are low in these upper two units.

Traces of charcoal were also intermittently present from Unit 8 upwards (Fig. 5), with two sharp increases in charcoal levels are evident. The first occurs within Unit 9, peaking towards the top of the unit. Charcoal was absent from Units 10 and 11, corresponding with a similar decline in phytoliths and an increase in grain size. A second, less significant charcoal peak is evident at the top of Unit 12 (Fig. 5).

\subsection{Non-marine mollusca and ostracoda}

Comminuted shell debris was present throughout the Phase 2 and 3 deposits at MDF-61 (Table 1). The highest densities were present in samples taken between 1.9 and $1.5 \mathrm{~m}$ (units 3-5). The largest identifiable fragments resembled the thick shells of Melanoides sp., although none were sufficiently well preserved to allow confident species attribution; however, it is highly likely that the common species Melanoides tuberculata is represented. Small shell fragments were also evenly scattered through the lower part of the Phase 3 deposits, occurring throughout units 9 and 10. Non-marine ostracods were also present a various levels (Table 1). The assemblages consisted almost entirely of the smooth form of the euryhaline species Cyprideis torosa. A particularly rich horizon, from which hundreds of $C$. torosa valves and carapaces were preserved, occurred at $1.5 \mathrm{~m}$ within Unit 5 (Fig. 5). Occasional valves of freshwater ostracod species were encountered in the richest horizons (Table 1 ).

\section{Luminescence dating}

Four samples from the MDF-61 sequence were selected for luminescence dating. Ages were obtained using single aliquot regeneration OSL measurements, multigrain aliquots and single grains, along with a simplified SAR thermally-transferred OSL (TTOSL) technique (cf. Porat et al., 2009; Rosenberg et al., 2011b). An additional sample (MUN13-BLEACH) was collected from aeoliantransported surface sediment, in order to measure any unbleachable ('residual') TT-OSL signal.

\subsection{Sample preparation}

Samples for age determinations were collected by hammering opaque steel tubes into the cleaned sections, in locations chosen to avoid modern bioturbation and visible sediment fissures. Sample preparation and measurements were carried out at the Luminescence Dating Laboratory (Research Laboratory for Archaeology and the History of Art, University of Oxford) under subdued sodium $(588 \mathrm{~nm})$ and LED (590 nm) lighting. Light-exposed ends were removed and dried in an oven to determine water content, and a 10-15 g portion was retained and analysed for radioisotope concentration (see below). All samples were wet sieved, after which the $180-255 \mu \mathrm{m}$ grains were subjected to hydrochloric acid (10\%) digestion of carbonates, hydrofluoric acid etching (60\% concentration for $90 \mathrm{~min}$ ) to remove the alpha-irradiated grain surfaces, and dry sieving to remove grain fragments $<180 \mu \mathrm{m}$ in size.

\subsection{Equivalent dose determination}

Measurements were performed on a Risø TL/OSL TL-DA-15 Mini-sys reader fitted with a single grain attachment (BøtterJensen et al., 2000). The reader is equipped with an LED stimulation unit comprising NISHIA blue LEDs (NSPB-500S, $470 \Delta 20 \mathrm{~nm}$ ) and infrared LEDs $\left(875 \mathrm{~nm}, 135 \mathrm{mWcm}^{-2}\right.$ ) (Bøtter-Jensen et al., $2000,2003)$, as well as a green $(532 \mathrm{~nm})$ solid state, diodepumped laser ( $\left.10 \mathrm{~mW}, \mathrm{Nd}: \mathrm{YVO}_{4}\right)$ for single grain measurements. Green long pass filters (GG-420) attached to the blue LEDs and a $7.5 \mathrm{~mm}$ Hoya U-340 bandpass filter separate the desired ultraviolet signal from the stimulation light. Emissions were detected with an EMI Electronics photo-multiplier tube (9235/0158/19747.0020). Samples were irradiated with the reader's ${ }^{90} \mathrm{Sr} /{ }^{90} \mathrm{Y}$ beta source $\left(0.041 \mathrm{~Gy} \mathrm{~s}^{-1}\right)$, which was calibrated for multigrain and single grain 
Table 1

Fossil remains from MDF-61.

\begin{tabular}{|c|c|c|c|c|c|c|c|}
\hline \multicolumn{4}{|l|}{ Section A } & \multicolumn{4}{|l|}{ Section B } \\
\hline Sample depth & Mollusca & Ostracoda & Foraminifera & Sample depth & Mollusca & Ostracoda & Foraminifera \\
\hline $10 \mathrm{~cm}$ & & & & $140 \mathrm{~cm}$ & & & \\
\hline $20 \mathrm{~cm}$ & & & & $150 \mathrm{~cm}$ & + & +++ & + \\
\hline $30 \mathrm{~cm}$ & + & & & $160 \mathrm{~cm}$ & & & \\
\hline $40 \mathrm{~cm}$ & + & & & $170 \mathrm{~cm}$ & & + & \\
\hline $50 \mathrm{~cm}$ & & & & $180 \mathrm{~cm}$ & & & \\
\hline $60 \mathrm{~cm}$ & & & & $190 \mathrm{~cm}$ & + & + & \\
\hline $70 \mathrm{~cm}$ & ++ & & & $200 \mathrm{~cm}$ & & & \\
\hline $80 \mathrm{~cm}$ & & & & $210 \mathrm{~cm}$ & & + & \\
\hline $90 \mathrm{~cm}$ & + & & & $220 \mathrm{~cm}$ & & + & + \\
\hline $100 \mathrm{~cm}$ & & & & $230 \mathrm{~cm}$ & & & \\
\hline $110 \mathrm{~cm}$ & & & & $240 \mathrm{~cm}$ & & & \\
\hline $120 \mathrm{~cm}$ & & & & $250 \mathrm{~cm}$ & & & \\
\hline $130 \mathrm{~cm}$ & & & & & & & \\
\hline
\end{tabular}

$+=$ present, $++=$ common, $+++=$ abundant.

measurements by one of the authors (LC-B) within the last two years; this and previous single grain calibrations revealed no detectable spatial heterogeneity in irradiation strength, therefore all grain positions were calibrated with a single value.

OSL measurements were made using $4 \mathrm{~mm}$ diameter multigrain aliquots and single grains using the single aliquot regeneration (SAR) protocol (Murray and Wintle, 2000); SAR TT-OSL (Porat et al., 2009; Rosenberg et al., 2011b) measurements were made using $6 \mathrm{~mm}$ diameter multigrain aliquots (Fig. 6). The measurement parameters for the SAR OSL equivalent dose measurements (both multigrain and single grain) and the simplified SAR thermally transferred TT-OSL protocol are given in Table 2. Dose response curves comprise at least four regeneration steps, with further points used if necessary to bracket the normalized natural response or test for saturation. Each OSL and TT-OSL dose response curve also incorporated a repeat and zero dose step, and OSL measurements included an IR depletion step (Duller, 2003). Initial measurements used a preheat regime similar to conditions used successfully for previously published luminescence dating studies upon quartz from Saudi Arabia (Petraglia et al., 2011, 2012). These conditions were subsequently tested with a dose recovery experiment (see below) and found to be suitable.

Luminescence Analyst v. 4.11 was used to analyse OSL and TTOSL data. OSL signal and background integration periods were the first $0.48 \mathrm{~s}$ and last $12 \mathrm{~s}$, and first 0.05 and last $0.18 \mathrm{~s}$ for multigrain and single grain data, respectively. Following Rosenberg et al. (2011b) and Porat et al. (2009), early background subtraction was used for the TT-OSL data (Ballarini et al., 2007a), with the signal comprising the first $1.2 \mathrm{~s}$ and the background the next $4.4 \mathrm{~s}$. An extra measurement error factor of $2 \%$ was included in the dose response points. All aliquots and grains were tested against rejection criteria (Table 3); these were accepted for analysis if the following conditions were met:

1. The net natural test dose signal was greater than three times the standard deviation of the background.

2. The natural test dose error was less than $20 \%$ of the test dose response.

3. Recycling ratio: the ratio of the repeated dose step to the first given dose ('recycling ratio') was within $10 \%$ of unity, or the recycling ratio was consistent with unity at 2 sigma.

4. Zero ratio: the ratio of the normalized OSL response of the zero dose step to the natural signal ('zero ratio') was less than a threshold value of $5 \%$ for OSL and $10 \%$ for TT-OSL, or the zero ratio was consistent with 0 at 2 sigma.

5. IR depletion ratio (excluded for TT-OSL): the ratio of the post-IR repeated dose step to the first given dose ('IR depletion ratio') was greater than 0.9 , or the IR depletion ratio was consistent with unity at 2 sigma.

6. Saturation: only non-saturated aliquots were included in the dating population. Aliquots were considered to be saturated if either the natural response plus error was greater than the fitted exponential (i.e. Luminescence Analyst returned an infinite error) or the dose response curve never reached the level of the natural signal (Yoshida et al., 2000).

7. Equivalent dose error was less than $50 \%$ of the equivalent dose (single grain only).

An equivalent dose $\left(D_{e}\right)$ was then calculated for each sample by applying the central age model (Galbraith et al., 1999) to the a)

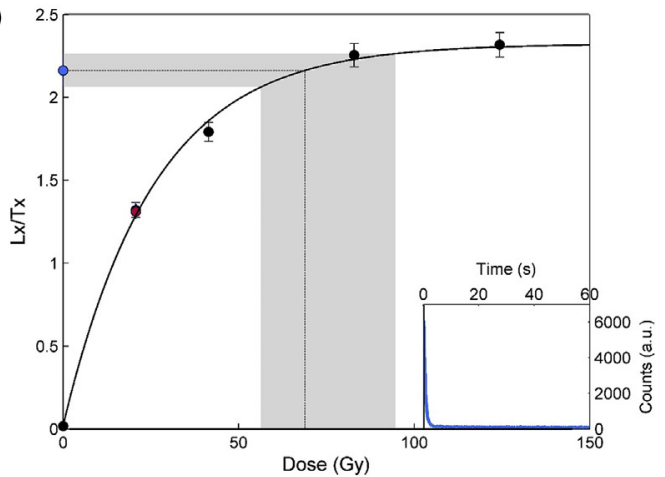

b)

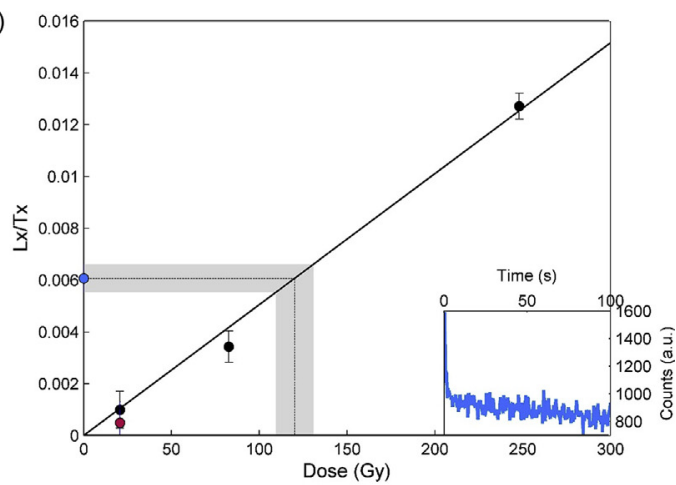

Fig. 6. Dose responses and decay curves (inset) for a: OSL and b: TT-OSL protocols for representative multigrain aliquots of MUN13-OSL8. 
Table 2

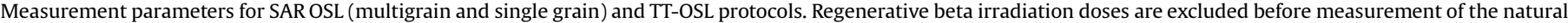
luminescence signal, and the IRSL [square brackets] is measured only during the IR-depletion ratio dose step.

\begin{tabular}{|c|c|c|}
\hline \multicolumn{2}{|l|}{ OSL } & \multirow{2}{*}{$\frac{\text { TT-OSL }}{\text { Multigrain aliquots }}$} \\
\hline Multigrain aliquots & Single grains & \\
\hline B Irradiation (Regeneration) & B Irradiation (Regeneration) & B Irradiation (Regeneration) \\
\hline Preheat & Preheat & Preheat \\
\hline $260^{\circ} \mathrm{C}\left(\right.$ Ramp $5^{\circ} \mathrm{Cs}^{-1}$, Hold $\left.10 \mathrm{~s}\right)$ & $260^{\circ} \mathrm{C}\left(\right.$ Ramp $5{ }^{\circ} \mathrm{Cs}^{-1}$, Hold $\left.10 \mathrm{~s}\right)$ & $200^{\circ} \mathrm{C}\left(\right.$ Ramp $5^{\circ} \mathrm{Cs}^{-1}$, Hold $\left.10 \mathrm{~s}\right)$ \\
\hline [IRSL] & [IRSL] & OSL \\
\hline $50^{\circ} \mathrm{C}, 100 \mathrm{~s}$ LED stimulation & $50^{\circ} \mathrm{C}, 100 \mathrm{~s}$ LED stimulation & $125^{\circ} \mathrm{C}, 300 \mathrm{~s}$ LED stimulation \\
\hline OSL & OSL & Preheat \\
\hline $125^{\circ} \mathrm{C}, 60 \mathrm{~s}$ LED stimulation & $125^{\circ} \mathrm{C}, 1 \mathrm{~s}$ laser stimulation & $\begin{array}{l}260^{\circ} \mathrm{C}\left(\text { Ramp } 5^{\circ} \mathrm{C} \mathrm{s}^{-1}, \text { Hold } 10 \mathrm{~s}\right) \\
\mathrm{TT}-\mathrm{OSL} \\
125^{\circ} \mathrm{C}, 100 \mathrm{~s} \text { LED stimulation }\end{array}$ \\
\hline B Irradiation (Test) & B Irradiation (Test) & B Irradiation (Test) \\
\hline $14.50 \pm 0.29 \mathrm{~Gy}$ & $15.97 \pm 0.32$ Gy & $14.50 \pm 0.29 \mathrm{~Gy}$ \\
\hline Preheat & Preheat & Preheat \\
\hline $240^{\circ} \mathrm{C}\left(\right.$ Ramp $5^{\circ} \mathrm{Cs}^{-1}$, Hold $\left.10 \mathrm{~s}\right)$ & $240^{\circ} \mathrm{C}\left(\operatorname{Ramp} 5^{\circ} \mathrm{C} \mathrm{s}^{-1}\right.$, Hold $\left.10 \mathrm{~s}\right)$ & $220^{\circ} \mathrm{C}\left(\operatorname{Ramp} 5^{\circ} \mathrm{C} \mathrm{s}^{-1}\right.$, Hold $\left.10 \mathrm{~s}\right)$ \\
\hline OSL & OSL & OSL \\
\hline $125^{\circ} \mathrm{C}, 60 \mathrm{~s}$ LED stimulation & $125^{\circ} \mathrm{C}, 1 \mathrm{~s}$ laser stimulation & $\begin{array}{l}125^{\circ} \mathrm{C}, 100 \mathrm{~s} \text { LED stimulation } \\
\text { Heat } \\
300^{\circ} \mathrm{C}\left(\text { Ramp } 5^{\circ} \mathrm{C} \mathrm{s}^{-1}, \text { Hold } 100 \mathrm{~s}\right)\end{array}$ \\
\hline
\end{tabular}

accepted population. Final site ages were estimated from multigrain OSL and TT-OSL data, while single grain data were used primarily to evaluate age reliability.

\subsection{Dose recovery experiments}

Both OSL and TT-OSL dose recovery experiments were performed. For SAR OSL, three multigrain aliquots $(4 \mathrm{~mm})$ were prepared from each OSL age sample (excluding the modern surface sediments). All aliquots were bleached together for 500s in sunlight (UK, sunny conditions), after which each set of three was irradiated with a dose within $5 \mathrm{~Gy}$ of preliminary OSL $\mathrm{D}_{\mathrm{e}}$ estimates for that sample (Table 4). For the TT-OSL dose recovery, six aliquots (6 mm) were prepared from surface sample MUN13-BLEACH and irradiated. SAR OSL and TT-OSL measurement and data analysis protocols have already been described.

\subsection{Dose rate calculations}

Gamma dose rates (Table 5) were measured on-site for each sample using a Canberra Inspector 1000. The gamma spectrometer was calibrated using the doped concrete blocks at the University of Oxford (Rhodes and Schwenninger, 2007), and gamma dose rates were calculated using the threshold technique (Mercier and Falguères, 2007; Duval and Arnold, 2013). Elemental concentrations were determined via ICP analysis and beta dose rates (Table 5) were calculated from these concentrations using the conversion factors of Adamiec and Aitken (1998) and attenuation values from Brennan (2003). Alpha dose rates were considered to be negligible due to grain etching. Due to the shallow depth of certain samples and the relatively low beta and gamma dose rates, both hard and soft components of the cosmic ray dose rate were calculated (Prescott and Stephan, 1982; Prescott and Hutton, 1988, 1994). Sediment density was assumed to be $1.9 \mathrm{~g} \mathrm{~cm}^{-3}$. However, the

Table 3

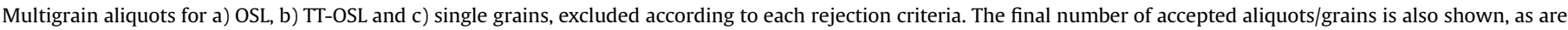
overdispersion and CAM De.

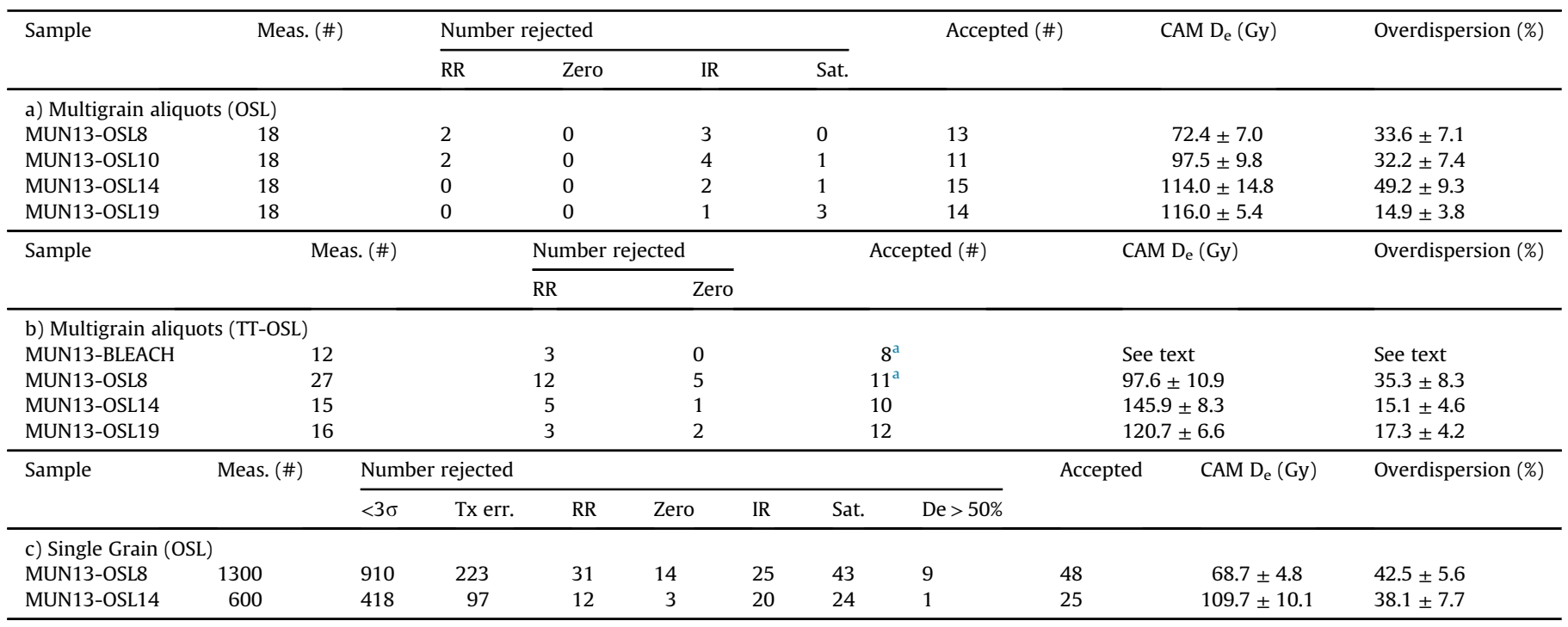

\footnotetext{
a 1 each excluded for noisy growth curve.
} 
Table 4

Dose recovery data for a) OSL and b) TT-OSL samples.

\begin{tabular}{|c|c|c|c|c|c|c|c|}
\hline \multirow[t]{2}{*}{ Sample } & \multirow[t]{2}{*}{ Meas. (\#) } & \multirow[t]{2}{*}{ Given dose (Gy) } & \multicolumn{3}{|c|}{ Number rejected } & \multirow[t]{2}{*}{ Accepted (\#) } & \multirow{2}{*}{$\begin{array}{l}\text { Normalized recovered } \\
\text { dose (mean } \pm 1 \mathrm{~s} \mathrm{~d} \text {.) }\end{array}$} \\
\hline & & & $\mathrm{RR}$ & Zero & IR & & \\
\hline \multicolumn{8}{|l|}{ a) OSL } \\
\hline MUN13-OSL8 & 3 & $58.0 \pm 1.2$ & 0 & 0 & 1 & 2 & $0.96 \pm 0.02$ \\
\hline MUN13-OSL10 & 3 & $91.1 \pm 1.8$ & 0 & 0 & 1 & 2 & $1.02 \pm 0.07$ \\
\hline MUN13-OSL14 & 3 & $107.6 \pm 2.2$ & 0 & 0 & 0 & 3 & $1.06 \pm 0.11$ \\
\hline MUN13-OSL19 & 3 & $107.6 \pm 2.2$ & 0 & 0 & 1 & 2 & $0.94 \pm 0.06$ \\
\hline All & 12 & - & $\mathbf{0}$ & $\mathbf{0}$ & 3 & 9 & $1.00 \pm 0.08$ \\
\hline \multicolumn{8}{|l|}{ b) TT-OSL } \\
\hline MUN13-BLEACH & 6 & $146.2 \pm 2.9$ & 0 & 0 & 0 & 6 & $0.97 \pm 0.09$ \\
\hline
\end{tabular}

effect of overburden erosion does not significantly affect final dose rate (and therefore age) estimates.

All as-found water contents were less than $1 \%$ (mass water/mass wet sediment). In order to account for higher attenuation during humid periods, dose rates were calculated assuming an average water content of $5.0 \pm 3.0 \%$. The water content correction factors of Aitken (1985) were used both to calculate dose rate attenuation for calculated beta dose rates and to correct on site gamma spectrometer measurements. Standard errors of 5\% were used for onsite gamma spectrometer measurements and elemental concentrations. Cosmic ray dose rate error was calculated via Monte Carlo techniques (5000 cycles). Standard errors of $5 \mathrm{~m}$ for altitude, $25 \mathrm{~cm}$ for overburden depth and $0.2 \mathrm{~g} \mathrm{~cm}^{-3}$ for sediment density were assumed for model inputs.

\subsection{Results}

\subsubsection{Equivalent dose measurements}

6.5.1.1. Multigrain OSL. Dose recovery results (Table 4a) suggest that the SAR OSL protocol is valid for the tested irradiation values. Nine of twelve measured aliquots were accepted (a minimum of two accepted per sample), with three rejected for unsuitable IRdepletion ratios. If each sample is considered individually, the mean normalized recovered dose is within $10 \%$ of unity, and consistent with unity at the 2 sigma range. If all aliquots are considered as a single population, the given dose is recovered with high accuracy $(1.00 \pm 0.08)$. Based on these results, the preheat regime of the SAR OSL protocol is believed to be appropriate for these samples, although this experiment is not sufficient to exclude the possibility of age underestimation due to grain saturation (see below). Eighteen aliquots were measured for each of samples MUN13-OSL8, OSL10, OSL14, and OSL19. OSL signals were fast component dominated (Fig. 6). Aliquots were rejected primarily for IR depletion ratio (Table 3), although the number of saturated aliquots increases with stratigraphic depth. Overdispersion values range from approximately 15\% (MUN13-OSL19) to a high of nearly 50\% (MUN13-OSL14) (Table 3, Fig. 7).
6.5.1.2. Single grain OSL. Single grains were measured for samples MUN13-OSL8 (1300 grains) and MUN13-OSL14 (600 grains). Between $80 \%$ and $90 \%$ of grains were rejected for dimness-related criteria (see above), and approximately $4 \%$ of grains were accepted to determine the final equivalent dose (Table 3). Considering only accepted grains, overdispersion values are similar for both samples: $42.5 \pm 5.6 \%$ and $38.1 \pm 7.7 \%$ for MUN13-OSL8 and MUN13-OSL14, respectively. Such luminescence characteristics are typical for single grain studies of quartz from the Arabian Peninsula (Armitage et al., 2011; Rosenberg et al., 2011b; Petraglia et al., 2012). Measured equivalent doses for both samples span a large range but are largely symmetric (weak positive skew in both samples) and unimodal (Fig. 7). It is therefore appropriate to use the central age model to obtain a central $D_{e}$ for this data. Given the uncertainty in the data, single grain CAM $\mathrm{D}_{\mathrm{e}}$ 's are indistinguishable from the multigrain data (see below).

6.5.1.3. TT-OSL. TT-OSL measurements were made for samples MUN13-OSL8, -OSL14, and -OSL19 until at least 10 aliquots per sample were accepted. The TT-OSL dose recovery experiment indicates that the chosen protocol can accurately recover a given dose (Table $3 \mathrm{~b}$ ), and it has been used successfully (with slightly different signal and background integration times) for a number of samples collected from sites in the Arabian Peninsula (Rosenberg et al., 2011a, b). Rosenberg et al. (2011b) have suggested that the SAR sensitivity correction (Porat et al., 2009) should not be used to determine $D_{e}$ values greater than $300 \mathrm{~Gy}$ for quartz from the Arabian peninsula, but all measured $\mathrm{D}_{\mathrm{e}}$ values were well below this limit. Overdispersion values varied between $15 \%$ and $35 \%$, which correspond well with the range of values (9\%-36\%) reported for Pleistocene samples from this region (Rosenberg et al., 2011b).

Equivalent doses were also measured from twelve aliquots of surface sample MUN13-BLEACH in order to determine the magnitude of any residual, unbleachable signal. These aliquots were measured and analysed in the same manner as those for age determination. Six of the eight accepted aliquots had equivalent doses indistinguishable from 0 at 1 sigma, and two yielded $D_{e}$

Table 5

Values used for dose rate calculations and final dose rates, in stratigraphic order.

\begin{tabular}{|c|c|c|c|c|c|c|c|c|}
\hline Sample & $\mathrm{K}(\%)$ & Th (ppm) & $\mathrm{U}(\mathrm{ppm})$ & $\begin{array}{l}\text { Depth } \\
(\mathrm{m})^{\mathrm{a}}\end{array}$ & $\begin{array}{l}\text { Beta } \\
\left(\mathrm{Gy} \mathrm{ka}^{-1}\right)\end{array}$ & $\begin{array}{l}\text { Gamma } \\
\left(G_{y ~ k a}{ }^{-1}\right)\end{array}$ & $\begin{array}{l}\text { Cosmic } \\
\left(\mathrm{Gy} \mathrm{ka}^{-1}\right)\end{array}$ & $\begin{array}{l}\text { Total wet dose } \\
\text { rate }\left(\mathrm{Gy} \mathrm{ka} \mathrm{ka}^{-1}\right)\end{array}$ \\
\hline MUN13-OSL8 & 0.322 & 1.18 & 1.03 & 0.22 & $0.36 \pm 0.02$ & $0.37 \pm 0.02$ & $0.22 \pm 0.01$ & $0.94 \pm 0.03$ \\
\hline $\begin{array}{l}\text { MUN13- } \\
\text { OSL10 }\end{array}$ & 0.629 & 1.80 & 1.80 & 0.48 & $0.66 \pm 0.05$ & $0.46 \pm 0.03$ & $0.21 \pm 0.01$ & $1.34 \pm 0.05$ \\
\hline $\begin{array}{r}\text { MUN13- } \\
\text { OSL14 }\end{array}$ & 0.869 & 1.90 & 2.00 & 0.96 & $0.85 \pm 0.06$ & $0.59 \pm 0.04$ & $0.20 \pm 0.01$ & $1.63 \pm 0.07$ \\
\hline MUN13- & 0.619 & 1.14 & 0.85 & 0.57 & $0.54 \pm 0.04$ & $0.47 \pm 0.03$ & $0.21 \pm 0.01$ & $1.21 \pm 0.05$ \\
\hline
\end{tabular}

OSL19

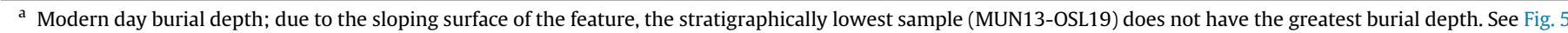
for stratigraphic sequence. 
a)
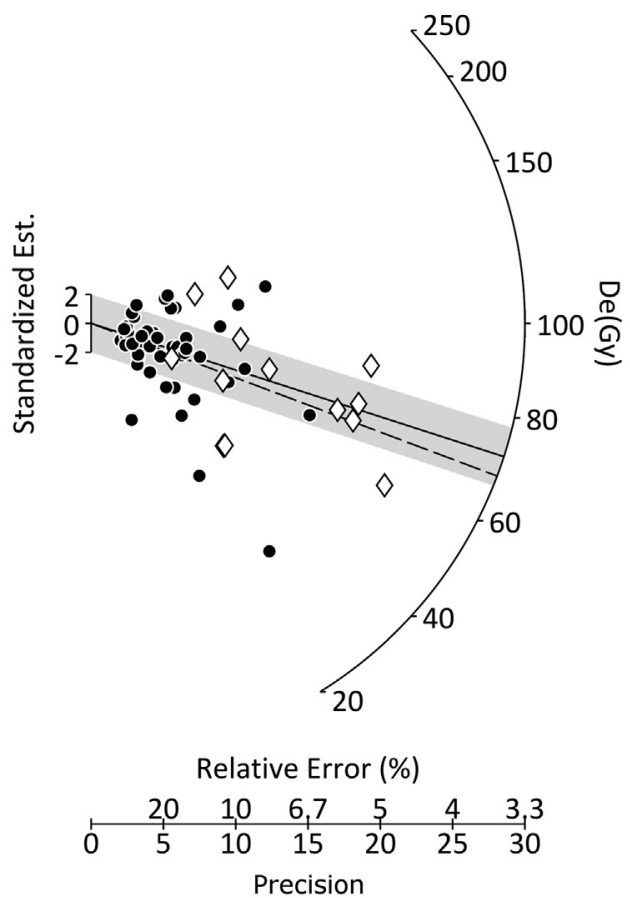

c)

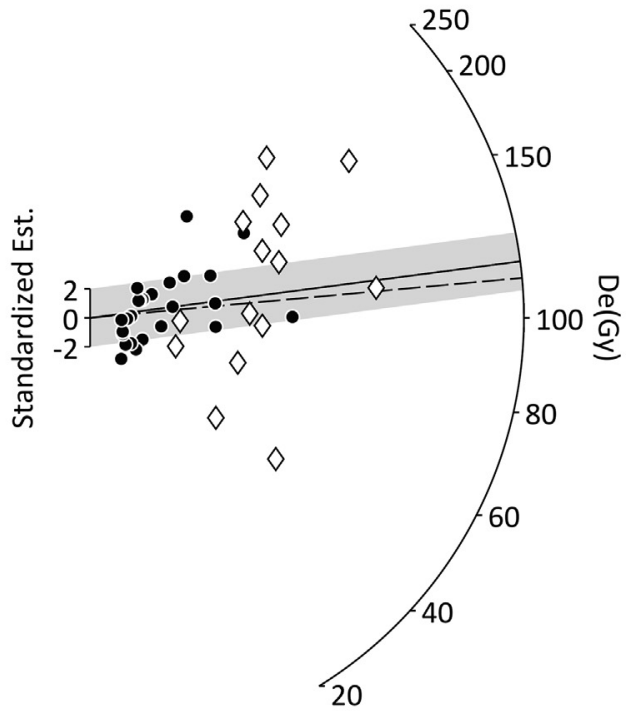

b)
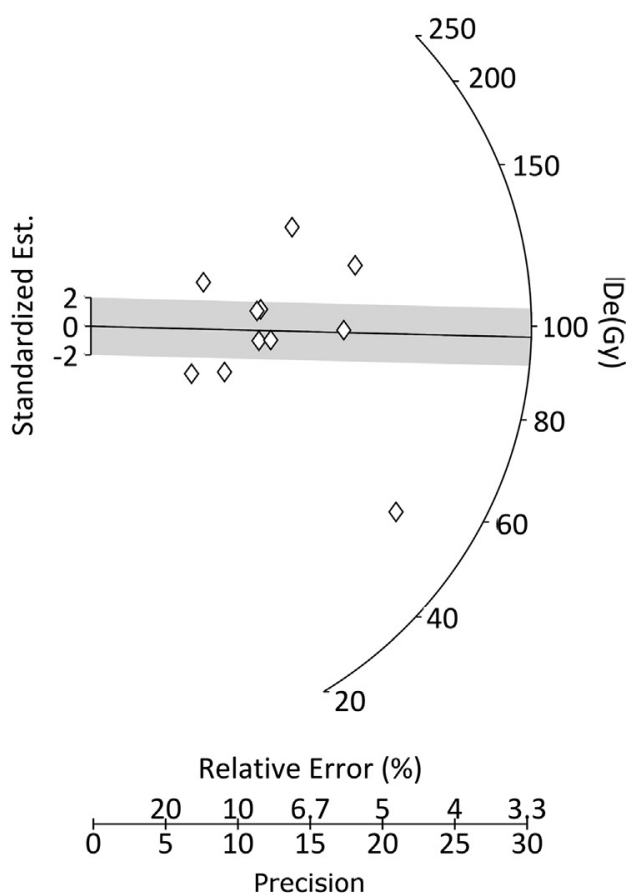

d)
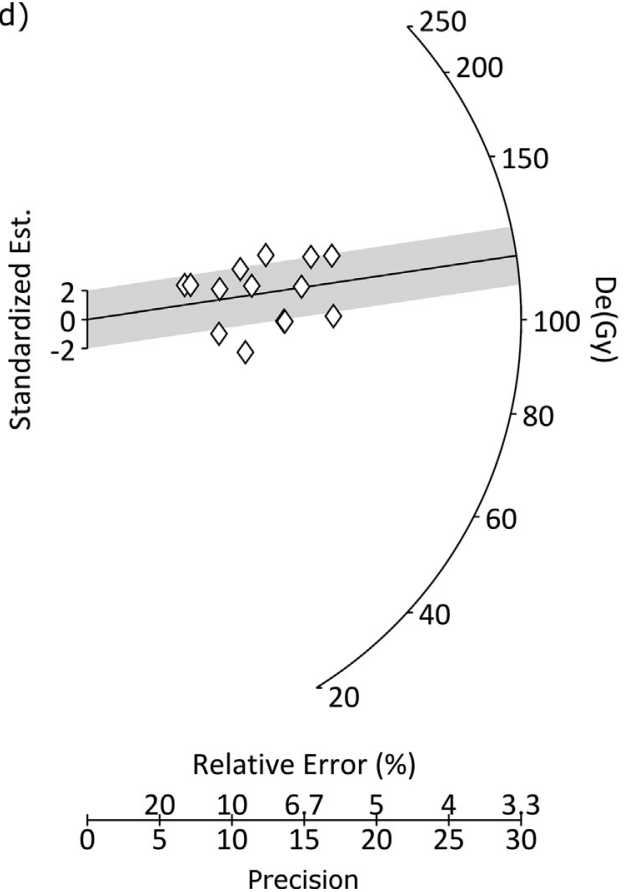

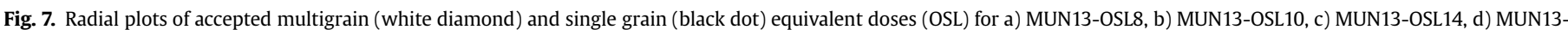

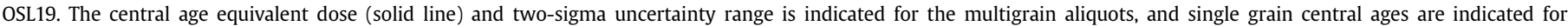
comparison (dotted line).

values of $18.7 \pm 7.8$ and $14.9 \pm 4.8 \mathrm{~Gy}$. There is no evidence for a systematic residual dose. Moreover, the accuracy of the dose recovery data indicates that if any residual is present in this modern surface sample, it is small in comparison with intrinsic $D_{e}$ scatter for equivalent doses of $>100 \mathrm{~Gy}$. Although Rosenberg et al. (2011b) reported an unbleachable residual of $5.5 \pm 2.6 \mathrm{~Gy}$ for quartz from the Arabian Peninsula, the data reported in this paper does not require a similar systematic correction. Because MUN13-BLEACH comprises aeolian sediment, however, it cannot be used as a precise analogue for bleaching efficiency during site formation.
6.5.2. Equivalent dose accuracy: evidence from the comparison of multiple techniques

Two of the three samples measured using both TT-OSL and OSL techniques (Table 3 ) yielded TT-OSL equivalent doses that were significantly older than the corresponding OSL equivalent doses (no overlap at 1 sigma); both techniques provided similar $D_{e}$ values for the third sample. In addition, samples measured using single grain techniques provided equivalent central age $D_{e}$ estimates for both multigrain and single grain SAR OSL. When final ages were calculated (see Section 8), TT-OSL ages were equivalent throughout the 
sequence given the age uncertainties, but an age reversal was evident for the quartz OSL ages (both multigrain and single grain). The reliability of the measured equivalent doses is discussed below in light of the multiple analyses undertaken and known site characteristics. Effects due to saturation, partial bleaching, bioturbation and microdosimetry are considered.

6.5.2.1. OSL underestimation near saturation. Age inaccuracy due to saturation of the OSL signal must be considered for these samples. The presence of saturated multigrain aliquots increased with stratigraphic depth, and single grain data from MUN13-OSL8 and MUN13-OSL14 reveal that nearly half of grains which pass criteria one through five (acceptable quartz SAR characteristics) were saturated. The proportion of saturated grains was not significantly different between tested samples, even though the $D_{e}$ of MUN13OSL8 $(68.7 \pm 4.8 \mathrm{~Gy})$ is just over half of that calculated for MUN13-OSL14 (109.7 $\pm 10.1 \mathrm{~Gy}$ ). Dose response curves (single saturating exponential) are characterized by a wide range of $D_{0}$ values (ca $10 \mathrm{~Gy}$ to several hundred Gy), with a median of $49.0 \mathrm{~Gy}$ and a strongly positively skewed distribution. This wide range of single grain dose responses is typical for published data (Jacobs et al., 2003; Duller, 2012), although the high proportion of saturated grains at relatively low equivalent doses is unusual. Similar high proportions of saturated grains have also been reported for the site of Jebel Faya (Armitage et al., 2011), but not for sites in northern Saudi Arabia (cf. Petraglia et al., 2012).

Underestimation of luminescence ages due to signal saturation can be demonstrated via dose recovery experiments (Duller, 2012), and it has been suggested that equivalent doses $>2 \mathrm{D}_{0}$ should not be used in luminescence dating calculations (Wintle and Murray, 2006). Additionally, a study of multiple samples in the Arabian peninsula by Rosenberg et al. (2011b), suggested that multigrain OSL measurements begin to underestimate the true equivalent dose (measured via TT-OSL) due to saturation effects at $>100 \mathrm{~Gy}$. It is therefore plausible to consider OSL equivalent doses that are near this $100 \mathrm{~Gy}$ range as potential minimum estimates.

6.5.2.2. Partial bleaching. Partial bleaching of the OSL signals, which may cause age overestimation in luminescence studies (Olley et al., 1999; Bailey and Arnold, 2006; Ballarini et al., 2007), is unlikely to have affected these samples. Palaeoecological and sedimentological evidence suggest that samples MUN13-OSL8 and -OSL 10 were deposited under primarily aeolian conditions, with some evidence for water-lain sediment. Older samples MUN13OSL14 and -OSL19 consist of palustrine sediments deposited under relatively low energy, shallow-water conditions. Single grain OSL equivalent dose distributions (Fig. 7), which are both symmetric and concordant with multigrain $\mathrm{D}_{\mathrm{e}}$ estimates, do not support the hypothesis that sediment was only partially reset. It is possible, however, that partial bleaching may have affected the TTOSL signal, which is significantly less light-sensitive (Adamiec et al., 2008). This may explain the slight stratigraphic reversal of the topmost TT-OSL sample, which also provided the highest overdispersion values of the three samples analysed. However, this does not change the overall interpretation of the results.

6.5.2.3. Bioturbation. Evidence for bioturbation, such as ironstaining caused by the development of root systems, is apparent within certain stratigraphical units (Fig. 5). However, it is probable that this would have occurred near the time of the original deposition of these units and therefore not significantly affected OSL ages. Recent bioturbation, in the form of burrows filled with red sands, was clearly visible in the section due to the strong colour difference and the unconsolidated nature of the infilling sediments. Desiccation cracks were also apparent, which may have introduced small amounts of younger sediment into older layers, but large scale sediment mixing away from these features is unlikely. Although we cannot rule out the effect of bioturbation in postdepositional mixing of sediment from previously discrete layers, which may cause both upward and downward grain movements within the section (Bateman et al., 2007a, b; Rink et al., 2013), such effects are not evident in the single grain equivalent dose populations. Furthermore, a large proportion of ostracods tests recovered from the MDF-61 sequence were preserved as intact carapaces, suggesting that the majority of the sequence was deposited under low-energy conditions.

6.5.2.4. Microdosimetry. Beta dose heterogeneity is likely to have affected the overdispersion values measured for the MDF-61 samples. The range of beta radiation (several millimetres) is short enough that grains within a suitably heterogeneous sample may experience variable dose rates, an effect known as microdosimetry (Murray and Roberts, 1998; Lomax et al., 2007; Jacobs et al., 2008). Studies that have either physically tested or modelled the equivalent dose distribution effects caused by microdosimetry (Kalchgruber et al., 2003; Nathan et al., 2003; Mayya et al., 2006; Cunningham et al., 2012; Guérin et al., 2012) indicate significant effects on luminescene measurements. We suggest that a significant portion of the overdispersion noted in the single grain equivalent dose populations reported here is due to microdosimetric effects in coarse-grained, porous sediments with isolated feldspar grains (Cunningham et al., 2012; Guérin et al., 2012). Microdosimetric effects are also likely to have contributed to the high overdispersion in multigrain OSL data from sample MUN13OSL14, due to the presence of numerous small fragments of mollusc shell in the sediments. Nevertheless, these effects are unlikely to cause a systematic bias in the final age estimates.

6.5.2.5. Summary. Based on the measured equivalent dose distributions and site formation analysis described above, it is likely that discrepancies between OSL (multigrain and single grain) and TTOSL $D_{e}$ measurements are primarily due to underestimation of absorbed dose due to saturation effects. It is also possible that partial bleaching of the TT-OSL signal may have had an effect: the TT-OSL $D_{e}$ measured for sample MUN13-OSL8 is more than $20 \mathrm{~Gy}$ higher than that measured via OSL even though this sample yields an equivalent dose less than the apparent $100 \mathrm{~Gy}$ saturation limit. However, the concordance between the two techniques in the measured $D_{e}$ for sample MUN13-OSL19 suggests that any partial bleaching has not caused systematic age overestimates. Similarly, bioturbation and microdosimetric effects may be present, but are not likely to have caused systematic age biases.

\section{Archaeological evidence}

The spatial and temporal complexity of the Arabian Middle Palaeolithic record has become increasingly evident (Groucutt and Petraglia, 2012, 2014; Scerri et al., 2014a). Much recent research has been focused on the potential African affinities of certain Arabian Middle Palaeolithic assemblages; although few Arabian sites have been reliably dated, it has been argued that they correspond with the environmental amelioration of MIS 5 (e.g. Armitage et al., 2011; Rose et al., 2011; Crassard and Hilbert, 2013; Usik et al., 2013). Other Middle Palaeolithic assemblages have been regarded as not being self-evidently diagnostic in terms of cultural origins (e.g. Petraglia et al., 2011, 2012), and still others have suggested possibly Levantine origins for some Arabian assemblages (e.g. Crassard, 2009; see also; Delagnes et al., 2012). Quantified comparisons of Arabian and northeast African lithic assemblages have demonstrated a complex pattern of similarities and differences, with one site in northern 
Arabia (JSM-1, Jubbah) displaying consistent differences from all the other assemblage studied, but others displaying similarities with northeast African assemblages (Scerri et al., 2014a). The complexity of the Arabian Middle Palaeolithic record clearly suggests the operation of a number of influences. Some lithic variability is doubtless influenced by pragmatic factors such as raw material form and quality, although some of the variability is likely to be the result of cultural factors. Given the diversity of assemblage types seen in Arabia it must be hypothesized that the Peninsula saw a complex demographic history in the Late Pleistocene, probably with several waves of dispersal from different sources and complex interactions between these populations and others perhaps already in Arabia.

At MDF-61 the stratified archaeological material was buried up to a maximum depth of $0.55 \mathrm{~m}$. A total of 207 lithic artefacts in fresh condition were recovered from the calcareous silty sands (Units 9-12). Where the protective calcrete that caps the sequence had been eroded, numerous similar lithics occurred as a surface scatter, from which a further sample of 728 lithics was collected. These were in fresh condition, indicating that they had been exposed relatively recently. At two points of high artifact density, artefacts were systematically collected from $2 \times 2$ metre squares (Fig. 4), and to increase sample size, further examples of types such as cores, retouched flakes and Levallois flakes were collected from across the site (Table 6).

The collected lithic assemblage from MDF-61 consists of 935 artefacts (Fig. 8), 99\% of which were manufactured using highquality chert. The most likely source for this raw material are seams within the limestone bedrock of the Tuwayq escarpment, which crops out $\sim 10 \mathrm{~km}$ to the east of the site. As assemblage of 130 cores was collected, providing insights into the later stages of reduction. A large proportion of these ( $75 \%$, see Table S1) were Levallois cores, particularly recurrent centripetal (30\%) and preferential with centripetal preparation (22\%). Almost all of the cores were small and thin, and had been heavily reduced by these specific formal reduction methods. The different core types are similar in size and other morphological features (Table S2), suggesting a dual strategy of producing large preferential Levallois flakes alongside productive recurrent cores giving a large number of relatively large flakes. No evidence for Nubian Levallois or bifacial façonnage reduction was identified, while unidirectional-convergent reduction is only indicated by occasional scar patterns on flakes. The Levallois flakes $(\mathrm{n}=97)$ feature finely faceted striking platforms and mostly centripetal scar patterns, and are typically $\sim 50-60 \mathrm{~mm}$ long and ovoid to rectangular in shape (Fig. 9, Table S3). The standardized character of Levallois flakes at MDF-61 provides a clear technological signal, different from that of sites associated with, for example, 'Nubian Complex' and Levantine Late Middle Palaeolithic assemblages.

An important feature of the MDF-61 lithic assemblage is the high frequency of retouched tools. These are a rare component of Arabian Middle Palaeolithic assemblages because most of the sites attributed to this period in the region represent raw material procurement and early stage reduction localities. The retouched tool assemblage from MDF-61 therefore represents an important baseline for understanding the character of retouched lithics in this region. The sample of retouched tools $(n=79)$ demonstrates an emphasis on retouch of the lateral margins of flakes. In many cases this retouch trends towards denticulation. Many of the retouched flakes are convergently shaped, and some can be classified as retouched points.

The composition of the assemblage is shown in Table 6. The different collection units demonstrate some variability across the site, but also that the major categories occur at broadly similar frequencies. Further details of the archaeological material from MDF-61 are presented in the Supplementary Online Material.

\section{Synthesis}

\subsection{Age of the MDF-61 sequence}

Final ages are provided in Table 7 and the positions of these samples is shown on Fig. 5. Quartz multigrain OSL ages range from $77.1 \pm 8.0 \mathrm{ka}$ at the top to $95.6 \pm 5.9 \mathrm{ka}$ at the bottom of the dated sequence; TT-OSL ages range from $104.0 \pm 12.2 \mathrm{ka}$ to $99.5 \pm 6.8 \mathrm{ka}$. Age reversal in the upper samples is attributed to signal saturation (see above). Parsimoniously, the dated sequence is older than the uppermost quartz OSL age $(77.1 \pm 8.0 \mathrm{ka})$, and younger than the concordant OSL/TT-OSL ages obtained for MUN13-OSL19 $(95.6 \pm 5.9 \mathrm{ka}$ and $99.5 \pm 6.8 \mathrm{ka})$. A Bayesian statistical model (OxCal v4.2), incorporating the stratigraphical data, multigrain OSL and TT-OSL ages (see SOM 2 for code) suggests that site formation is most likely to have occurred between $\sim 97$ and $77 \mathrm{ka}$ (Fig. 10).

The OSL age estimates presented here therefore place the deposition of the majority of the MDF-61 sequence (Units 4-12) between $\sim 100 \mathrm{ka}$ and $80 \mathrm{ka}$, This site therefore provides evidence for wet savannah environments and the periodic existence of standing waterbodies within the Mundafan Basin during the later part of MIS 5 (between $\sim 100 \mathrm{ka}$ and $80 \mathrm{ka}$ ). The dates presented here are in agreement with previous research, which concluded that a waterbody covering an area up to $300 \mathrm{~km}^{2}$ existed in the Mundafan Basin at some point during MIS 5 (Rosenberg et al., 2011a). This is also consistent with palaeoclimatic evidence from elsewhere in the southern Arabian Peninsula, which indicates an increase in the northward latitudinal position and intensity of the monsoon system between $\sim 85$ and 75 ka (cf. Burns et al., 2001; Fleitmann et al., 2003; Fleitmann and Matter, 2009). The basal lacustrine sediments at MDF-61 remain undated, and it is unclear whether these represent an earlier part of MIS 5 (i.e. MIS 5e) or a still older Pleistocene wet phase.

\subsection{Palaeoenvironmental reconstruction}

The palaeoenvironmental and palaeoecological data from MDF61 described above demonstrate a number of significant changes to the local environment in the Mundafan Basin which can be ascribed to three phases of deposition (see Fig. 5).

Table 6

Typological breakdown of the MDF-61 lithic assemblage (percentages are shown in brackets, excluding chips and chunks).

\begin{tabular}{|c|c|c|c|c|c|}
\hline & Trench 1 & Square 1 & Square 2 & Other surface & Total \\
\hline Cores & $8(6)$ & $21(15)$ & $32(14)$ & 69 & 130 \\
\hline Flakes & $100(79)$ & $73(51)$ & $176(74)$ & 38 & 387 \\
\hline Levallois flakes & $4(3)$ & $8(6)$ & $2(1)$ & 83 & 97 \\
\hline Core management (débordant) flakes & $10(8)$ & $19(13)$ & $15(6)$ & 11 & 55 \\
\hline Chips/chunks & 81 & 5 & 100 & 1 & 187 \\
\hline Retouched & $4(3)$ & $21(15)$ & $14(6)$ & 40 & 79 \\
\hline Total & 207 & 147 & 339 & 242 & 935 \\
\hline
\end{tabular}



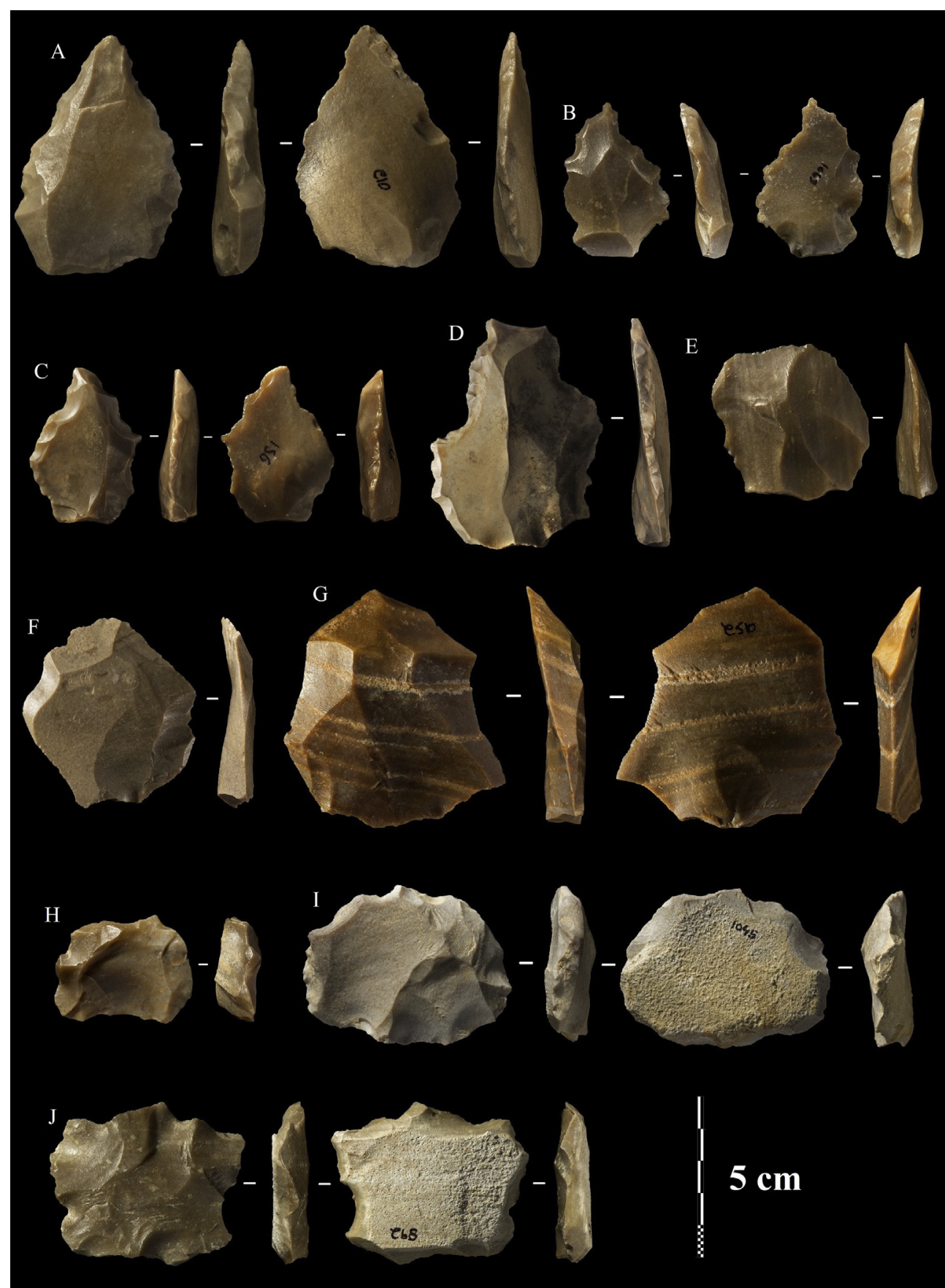

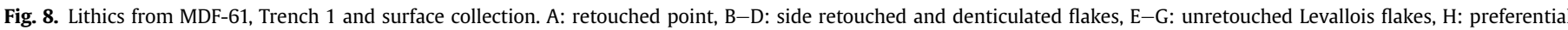
Levallois core with centripetal preparation, I-J: recurrent centripetal Levallois cores.

\subsubsection{Phase 1}

The earliest phase comprises lacustrine marls that preserve little evidence for vegetative processes. These are thought to represent a more substantial water body than that represented by the overlying shallow/littoral palustrine carbonates. No fossils remains were recovered and so the character of the local environment during Phase 1 remains unknown.

\subsubsection{Phase 2}

The succeeding intermediate depositional phase represents a palustrine environment characterized by the periodic presence of standing water-bodies. The characteristics of these facies are typical of palustrine carbonate formation within the littoral (shallow water) zone of low energy and low gradient lakes (Alonso-Zarza, 2003; Alonso-Zarza and Wright, 2010). In such shallow-water environments, the presence of littoral vegetation and episodic subaerial exposure initiate the pedogenesis of lacustrine carbonates. This is shown by peaks in organic carbon and corresponding peaks in phytolith content within Units 7 and 8 (Fig. 5), which probably reflect episodic (possibly seasonal) water level changes. Distinct increases in phytolith content at 0.8 and $0.6 \mathrm{~m}$ coincide with increased organic carbon values and reflect a landscape dominated by $C_{3}$ grassland with a tall mesic $C_{4}$ element (Fig. 5 ). The main morphotypes counted are predominantly found in $C_{3}$ taxa across the region, but also occur in some $\mathrm{C}_{4}$ types and therefore cannot solely be attributed to type. Importantly, trace levels of woody taxa 


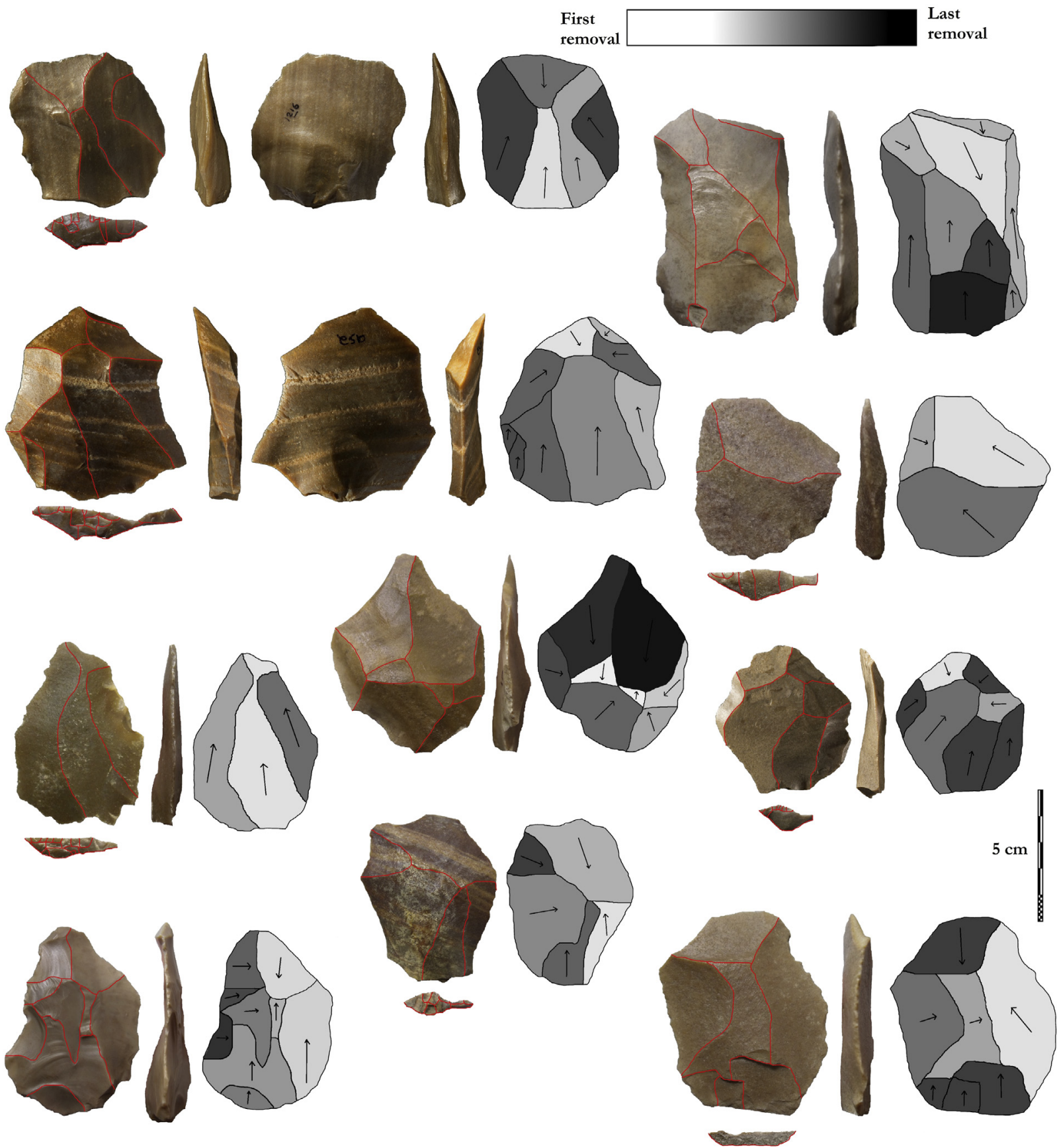

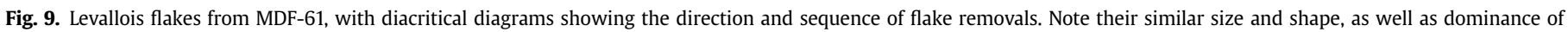
centripetal preparation.

are also present, indicative of shrubs or possibly trees in the surrounding area. The presence of shells of Melanoides sp. (probably $M$. tuberculata) in discrete concentrations throughout the Phase 2 palustrine facies, suggests the presence of shallow, probably

Table 7

Final ages calculated for all samples and techniques, in stratigraphic order.

\begin{tabular}{llll}
\hline \multirow{2}{*}{ Sample } & \multicolumn{2}{l}{ Age $(\mathrm{ka})$} & \\
\cline { 2 - 4 } & Multigrain (OSL) & Single grain (OSL) & Multigrain (TT-OSL) \\
\hline MUN13-OSL8 & $77.1 \pm 8.0$ & $73.1 \pm 5.8$ & $104.0 \pm 12.2$ \\
MUN13-OSL10 & $73.0 \pm 7.9$ & - & - \\
MUN13-OSL14 & $69.9 \pm 9.5$ & $67.2 \pm 6.8$ & $89.4 \pm 6.3$ \\
MUN13-OSL19 & $95.6 \pm 5.9$ & - & $99.5 \pm 6.8$ \\
\hline
\end{tabular}

seasonal waterbodies. Melanoides tuberculata is widespread throughout modern Arabia (Neubert, 1998) and Quaternary sedimentary deposits across Africa and Asia. It is a 'slum' species common in both evaporative and permanent waterbodies and is particularly tolerant of warmer waters, often occurring in ephemeral pools prone to desiccation (Dundee and Paine, 1977; de Kock and Wolmarans, 2009). The general impression of evaporative, saline bodies of standing water is supported by the almost monotypical ostracod assemblages recovered from throughout the sequence. These are dominated by Cyprideis torosa, a euryhaline species tolerant of salinities ranging from almost freshwater to hypersaline (Meisch, 2000). Furthermore, all of the $C$. torosa valves from MDF-61 were of the smooth variety, thought to indicate 

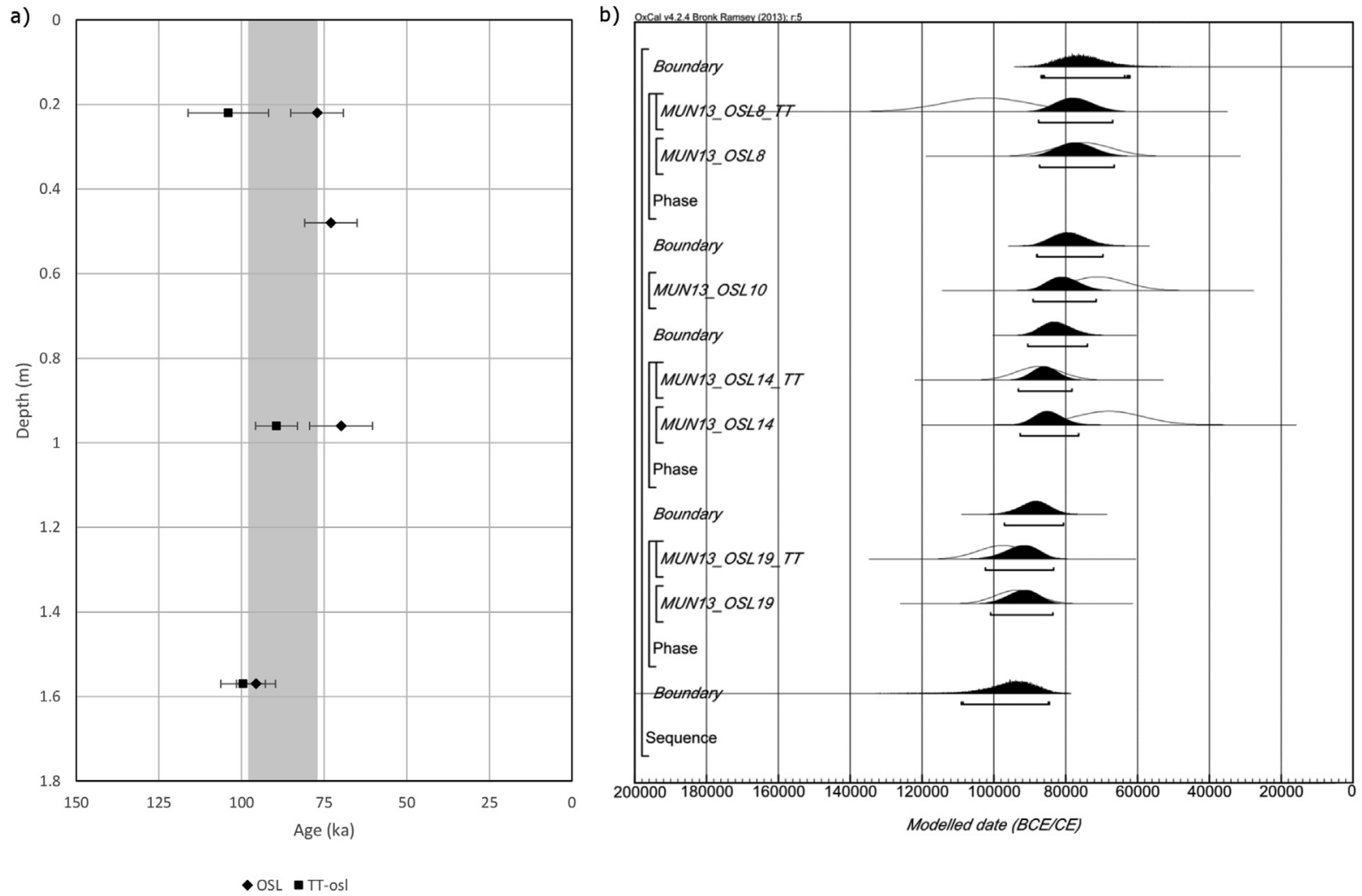

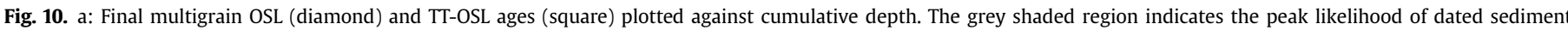

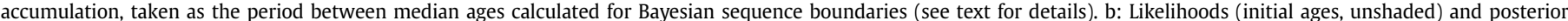
probabilities (modelled ages, black) for all ages and boundaries calculated via OxCal. For code see SOM 2.

salinities above 5\%o (Meisch, 2000; van Harten, 2000). The absence of mollusc or ostracod species indicative of more permanent bodies of freshwater suggests that such waterbodies were at best shortlived during the deposition of the Phase 2 deposits and were probably highly seasonal. Occasional valves of freshwater ostracods, such as Darwinula stevensoni and Paralimnocythere compressa, were probably flushed into bodies of standing water in the lower part of the basin by seasonally activated wadis. More humid periods at MDF-61 were characterized by a mosaic of vegetation consisting of $\mathrm{C}_{3}$ grasslands with woody elements (Fig. 5).

\subsubsection{Phase 3}

The palaeoenvironmental record indicates that shallow water/ palustrine conditions were then succeeded by terrestrial sedimentation, due to a retreat of lake water levels at the site location. This is shown by the archaeology-bearing Units 9-13, which comprise partly cemented, calcareous silts/sands with numerous iron-stained root voids, indicative of an incipient sandy palaeosol. Although there is evidence for vegetative processes at the site during this period, these units exhibit numerous desiccation cracks and carbonate nodules, suggesting that groundwater was exposed to increased evaporation. Similarly, sharp changes in susceptibility values and increases in sediment particle size, suggest abrupt variations in sediment influx to the site, possibly as a result of increased wind strength and aeolian transport. It is possible that the Mundafan basin still accommodated a lake at this time (Rosenberg et al., 2011a), although the evidence from MDF-61 indicates a markedly drier environment than during previous phases. Phytolith evidence from the Phase 3 deposits indicates an expansion of grassland with some scattered woody elements. These were dominated by $\mathrm{C}_{3}$ taxa, but also contained some tall mesic panicoid $\mathrm{C}_{4}$ elements with trace levels of arid-adapted $\mathrm{C}_{4}$ Chloridoid grasses (present in the lower part of Unit 9 only). Two circular crenate palm phytoliths were present at $0.45 \mathrm{~m}$ (Unit 9). It is unclear whether palm was established locally, although the rarity of phytoliths attributable to it suggests that it was not common within the Mundafan Basin. More likely explanations for the presence of palm phytoliths in the upper part of the MDF-61 sequence include long distance transport by wind, given that palm phytoliths are small (typically $\sim 5 \mu \mathrm{m}$ ). The presence of significant quantities of microscopic charcoal indicates that the site was affected by at least two burning episodes, the first during the deposition of Unit 9 and the second towards the top of Unit 12. Microscopic charcoal levels rise sharply at the base of Unit 9 and are present throughout this unit, peaking to the highest levels in the sequence. Macroscopic charcoal remains were not observed in the sequence, suggesting that the rise is due to burning of vegetation within the Mundafan region. Wildfires were probably caused by natural lighting strikes igniting seasonally desiccated vegetation, or from deliberate burning by humans in the surrounding landscape. There is a notable absence of charcoal and phytoliths in the sediments in the upper part of Unit 10 and all of Unit 11, with Unit 11 also representing an archaeologically sterile layer. This marks a phase of increased aridity at the site, also evidenced by an influx of coarse aeolian sand material and low organic carbon values. The overlying Units 12 and 13 are again typified by grassland environments with occasional woody taxa, and also contain evidence for burning within the Mundafan Basin. It is throughout these units that the highest densities of artefacts were recorded.

The sequence at MDF-61 is overlain by a highly weathered and indurated calcrete crust, reflecting a further increase in evaporative conditions and marking the end to enhanced humidity within the region. No phytoliths were found within the uppermost $5 \mathrm{~cm}$ of the sequence. While a precise age for the termination of pluvial 
conditions at Mundafan is absent, it is reasonable to suggest that this commenced towards the end of MIS 5a, and had occurred by the onset of MIS 4 (ca $75 \mathrm{ka}$ ). The evidence from MDF-61 indicates, therefore, that following lake contraction, the desiccation and pedogenesis of calcareous lacustrine material under increasingly arid conditions, led to the development of a surficial calcitic crust. As arid conditions prevailed, erosion and deflation of the surrounding aeolian material led to the formation of a landform that was inverted with respect to its original (palaeotopographic) relief and was raised up to $4 \mathrm{~m}$ above the basin floor.

\section{Discussion}

\subsection{Timing and extent of lake formation within the Mundafan Basin}

The sequence at MDF-61 provides an important record of palaeoenvironmental changes within the Mundafan Basin during late-MIS 5. Our data support previous studies that have suggested a phase of lake formation here at that time (cf. Rosenberg et al., 2011a; Crassard et al., 2013). The presence of a large waterbody during MIS 5 would have played a critical role in enabling the expansion of $H$. sapiens into the Arabian interior and beyond. The timing and extent of lake formation corresponds with a variety of palaeoclimatic evidence indicating that Arabia experienced increased humidity as a result of northward displacement of the monsoon system. The sedimentary record at MDF-61 indicates that a number of environmental changes occurred within the Mundafan Basin in response to changing climatic conditions. Initially higher lake levels were followed by a contraction of lake waters, evidenced by palaeoenvironmental data and a succession of depositional regimes, from deeper lacustrine (marls), to shallow/littoral (palustrine carbonates) and terrestrial/shoreline (silts/sands) conditions. The deposition of Middle Palaeolithic artefacts occurs at the onset of terrestrial sedimentation at the site, following a period of lake retreat and groundwater evaporation (indurated calcrete). The palaeoecological record shows that at the time of occupation, the Mundafan Basin was a grassland region with a woody component (possibly including palm), and that the region experienced at least two phases of burning. The presence of a large freshwater body at Mundafan during late-MIS 5, along with an expansion of grasslands and woody taxa, confirms that during this time the region maintained an ameliorated climate capable of supporting early human populations and a variety of flora.

\subsection{Local and regional environmental setting}

Throughout the Late Quaternary, such incursions of monsoon rainfall, driven by insolation changes directly coupled with glacial boundary conditions (Clemens and Prell, 2003; Fleitmann et al., 2003; Leuschner and Sirocko, 2003; Jennings et al., 2015; Parton et al., 2015a,b), led to the widespread activation of drainage systems and extensive lake formation in Arabia. Previous palaeoenvironmental studies (e.g. Burns et al., 2001; Fleitmann et al., 2003, 2011; Rosenberg et al., 2011a) have demonstrated that periods of increased humidity occurred during Marine Isotope Stages (MIS) 5e ( 128-115 ka), 5c ( 105-95 ka) and 5a ( 85-75 ka). During these periods, large lakes formed in central Oman and southern Saudi Arabia, providing favourable environmental conditions conducive to the spread of early human populations. At these times, the incursion of summer monsoon rainfall was probably sufficient to trigger at least seasonal lake formation at Mundafan, fringed by savannah grasslands, which may have reached a maximum extent of $\sim 300 \mathrm{~km}^{2}$, and a maximum depth of $\sim 30 \mathrm{~m}$ during MIS 5c (Rosenberg et al., 2011a) and was likely recharged by regional wadi activation (Breeze et al., 2015).
Although no lake deposits of MIS 5e age have been reported from Mundafan, evidence for lake formation at Khujaimah, $\sim 250 \mathrm{~km}$ to the east (Rosenberg et al., 2011a), confirms the potential for large freshwater bodies to have existed elsewhere in Arabia at that time. The primary source of water for the lake at Mundafan is via eastward flowing channels which drain the Asir Mountains to the west, while the adjacent Tuwayq Escarpment and the area to the east of this drain eastwards into the Empty Quarter (see Crassard et al., 2013 for detailed discussion of the palaeohydrology of the Mundafan region). Prior to the development of the surrounding dune fields, it is likely that the channels which drain into palaeolake Mundafan from the Asir Mountains, would have flowed past the southern tip of the Tuwayq escarpment at the southeastern end of the basin, along a broad north-west to south-east trending valley. Now obscured by dunes, this valley marks the course of an ancient river system that was developed long before the emplacement of the Rub' al-Khali dunes. The subsequent blocking of this channel by dunes led to the formation of a large closed basin, within which Lake Mundafan developed during subsequent humid periods (Crassard et al., 2013). Recharge of the Asir headwaters may have led to the extension of freshwater fluvial systems between Asir and Mundafan that may have also have acted as corridors for the movement of early communities, however, further archaeological and palaeoenvironmental studies from the Asir region would be required to support this supposition.

Utilizing the heights of the lake sediments reported by Rosenberg et al. (2011a), an SRTM DEM of the surrounding paleohydrology produced by Crassard et al. (2013), indicates a total lake extent of $\sim 58 \mathrm{~km}^{2}$ during the Holocene, $\sim 210 \mathrm{~km}^{2}$ at $80 \mathrm{ka}$, and $\sim 100 \mathrm{~km}^{2}$ at $100 \mathrm{ka}$. Crassard et al. (2013) state, however, that these are minimum estimates, and that the lake was almost certainly larger than the maximum height of the preserved sediments, given the significant amount of deflation that would have occurred since the lacustrine phases ceased. These findings also estimate that given the accommodation space within the basin, the maximum potential size of the lake is $\sim 346 \mathrm{~km}^{2}$, which is in keeping with the estimate suggested by Rosenberg et al. (2011a). It is also possible that several separate water bodies or an expansive wetland environment existed within this large basin, which might not always have constituted a single large lake. Numerous inverted relief features across the basin may support this notion; these features have been reported from similar desert settings and also attributed to the presence smaller ponded water bodies (e.g. Aref, 2003; Al Shuaibi et al., 2011). The position of Middle Paleolithic sites in the basin at Mundafan may be explained by a mixture of this topographic/sedimentary complexity and by the sites dating to the time of the contraction of the lake from its maximum extent.

\subsection{Timing of human occupation at MDF-61}

The evidence for human occupation at MDF-61 occurs towards the top of the sequence within the Phase 3 deposits, suggesting that people did not inhabit this particular site in the Mundafan Basin until MIS 5a. Human occupation at MDF-61 therefore appears to correspond with a period of more arid conditions, characterized by dry grassland environments. An archaeologically sterile layer (Unit 11) coincides with a phase of increased aridity at the site, represented by an influx of coarse aeolian sand and a corresponding absence of phytoliths and low organic carbon values (Fig. 5).

\subsection{Implications of the MDF-61 lithic assemblage for hominin behaviour}

MDF-61 adds a critical new reference point to the small but growing corpus of dated Middle Palaeolithic assemblages from 
Arabia. By intra- and inter-regional comparative analyses of these assemblages themes such as human dispersal and adaptation can be addressed. At MDF-61, the combination of a highly reduced assemblage (i.e. heavily reduced cores, diminutive lithics, high frequencies of retouch) with a high incidence of preserved cortex indicates that complete reduction sequences were carried out on site. The methods by which the cores were reduced, the morphological and technological characteristics of preferential flakes and the character of retouch all indicate cultural (learned) behavioural influences, which can be compared to surrounding regions in order to understand factors such as dispersal. In terms of core reduction strategies, for instance, the raw material could have been worked by other methods such as Nubian Levallois or bifacial reduction, but was instead repeatedly reduced by centripetal Levallois methods.

The location of the site on the southwestern margin of a seasonally wet grassland environment would have provided a topographic highpoint and allowed easy access to the basin and its contained resources. In contrast, the terrain on the steeper eastern side of the lake would have exhibited an abrupt transition between the water body and the Tuwayq Escarpment. Nonetheless, the limestone Tuwayq Escarpment was the likely source of the chert used for lithic production. Factors such as the high frequencies of retouch indicate that raw material was being used in an efficient manner and that tools were both being initially shaped and rejuvenated (resharpened) at MDF-61 suggesting repeated occupations of the site (although perhaps over a relatively short time period). Most Middle Palaeolithic localities at Mundafan are extremely low density scatters. In contrast MDF-61 has thousands of lithics, indicating that hominins were repeatedly attracted to this spot. Previous accounts have suggested correlations between Palaeolithic sites and lakes in Arabia, but not to specific positions in relation to the lake (e.g. Petraglia et al., 2011, 2012). An analogous explanation to that we have proposed for MDF-61 can be applied to other lakeside Middle Palaeolithic sites in Arabia. At JKF-1 in the Nefud Desert of northern Saudi Arabia hominins also transported lithics from a raw material source to the far side of a lake (Petraglia et al., 2012; Groucutt et al., 2015a). Elsewhere in the Nefud desert, Lower and Middle Palaeolithic lithic assemblages have been found associated with small lake basins (Scerri et al., 2015).

The typological, morphological and technological features of the MDF-61 lithics are similar to those of assemblages associated with fossils of H. sapiens in Africa and the Levant, as well as MIS 5 Middle Palaeolithic sites lacking fossils, such as Jwalapurum 22 in India (Groucutt et al., 2015b). The main characteristic shared between these assemblages is the combination of high frequencies of recurrent centripetal and centripetally prepared preferential Levallois methods of core reduction. Retouched tools are focused on side-retouched flakes and retouched points. This combination is found in East Africa by MIS 8, broadly contemporaneous with the origin of $H$. sapiens in the late Middle Pleistocene. With MIS 5 similar assemblages are found across the Saharo-Arabian belt and into India. Fossils associated with this combination of lithic features are assigned to H. sapiens (e.g. Omo-Kibish, Aduma, Haua Fteah, Qafzeh), while other hominin fossils (Neanderthals) in southwest Asia are instead associated with features such as high frequencies of unidirectional-convergent Levallois reduction (e.g. Yellen et al., 2005; Shea, 2008; Hovers, 2009; Nishiaki et al., 2012; Groucutt, 2014; Groucutt et al., in 2015b).

\subsection{Implications for models of human dispersal}

Current evidence indicates that $H$. sapiens was present in Africa by 200-150 ka (e.g. McDougall et al., 2005; Stringer, 2011), but questions remain as to how and when they left Africa to colonize Asia and beyond (e.g. Petraglia et al., 2010; Mellars et al., 2013).
Genetic evidence has produced conflicting results, with genealogies of single loci (such as mitochondrial DNA) generally being interpreted as indicating dispersal $\sim 60-50 \mathrm{ka}$ (Mellars et al., 2013), but whole genome analyses are consistent with much earlier dispersal (Scally and Durbin, 2012). Fossil evidence is rare, but demonstrates that $H$. sapiens was in the Levant in MIS 5, yet this can be interpreted as either representing a failed dispersal (Mellars et al., 2013), or as evidence of a far wider expansion into Asia (Petraglia et al., 2010). In the absence of fossil evidence, several claims have been made for African affinities in Asian archaeological material, in both eastern Arabia and India (Petraglia et al., 2007; Armitage et al., 2011; Rose et al., 2011; Crassard and Hilbert, 2013; Usik et al., 2013). The lack of similarity between these various assemblages - which differentially emphasize bifacial, Nubian and centripetal reduction - suggests a complex demographic process of dispersal out of Africa, subsequent adaptation and change, and/or that some of these assemblages were produced by hominins other than $H$. sapiens. Crucially, previous claims for 'African-like' technology in Arabia were of a rather different character to contemporary assemblages in the Levant and India (Armitage et al., 2011; Rose et al., 2011; Usik et al., 2013).

The MDF-61 assemblage provides not only the first stratified and dated human occupation in the Empty Quarter, but also a key reference point for lithic comparisons. The MDF-61 assemblage is the first to demonstrate distinct similarities between contemporaneous African, Levantine and Arabian assemblages, as well as late MIS 5 with material from the site of Jwalapurum 22 in southern India. MIS 5 sites with similar technological features to the MDF-61 assemblage are located close to both postulated northern and southern routes out of Africa (Fig. 1). H. sapiens could have moved through ameliorated northeast Africa (e.g. Wendorf et al., 1993) and the Sinai Peninsula (Kobusiewicz, 1999; Kobusiewicz et al., 2001). Alternatively, sites such as Aduma, Ethiopia (Yellen et al., 2005) are located close to the hypothesized Bab al Mandab route across the Red Sea. The current evidence is congruent with either, or both, of these dispersal routes having been used.

\section{Conclusions}

The MDF-61 record provides an important addition to knowledge of Late Pleistocene environments in interior Arabia. Although most of our current knowledge of this period has been obtained from southern and eastern regions, these areas may have been more sensitive to short term and localized climatic variability. They are therefore likely to have acted as population refugia, particularly the Yemeni highlands (Delagnes et al., 2012, 2013) and the Arabian Gulf (Rose, 2010; Armitage et al., 2011). Indeed the emerging archaeological record for these areas indicates a significant aspect of putatively autochthonous developments, perhaps suggesting that the interior areas are likely to be particularly fruitful if we wish to understand inter-regional population dispersals.

The presence of hominins in the interior of Arabia during MIS 5 between $\sim 100$ and $80 \mathrm{ka}$ is consistent with hypotheses placing dispersals of $H$. sapiens out of Africa during MIS 5 (e.g. Petraglia et al., 2010; Boivin et al., 2013). The lithic assemblage from MDF61 is another example of a stone tool technology similar to that found in east Africa (e.g. Shea, 2008), the Levant (Hovers, 2009; Shea, 2013) and India (Haslam et al., 2012; Petraglia et al., 2012), and reduces the 'outlier' status of the last two. Where dated, many of these examples of similar technology date to mid to later MIS 5. Alternatively, it has been suggested that sites such as MDF-61 represent a 'failed dispersal' that also saw $H$. sapiens expanding into the Levant during MIS 5 (Mellars et al., 2013). This suggests that this dispersal was not the narrow and localized dispersal to the 
Levant which has been envisaged, but a spatially and temporally broader and more complex process.

Given increasing evidence for complex Late Pleistocene demography, with various episodes of population interbreeding, considerable caution is needed in simplistically relating lithic typotechnological features to particular hominin species. Nevertheless, hypotheses can be developed and tested. Regardless of the origins of the early humans who made the Mundafan Al-Buhayrah lithic assemblage, our discovery demonstrates the importance of periodic climatic amelioration in the usually arid regions of the SaharoArabian belt (see also Groucutt and Blinkhorn, 2013; Scerri et al. 2014b; Parton et al., 2015a,b). The site of MDF-61 contributes further to the correlation of evidence for ancient human occupation and palaeohydrological features in Arabia. It also adds a further element to discussions of Arabian Late Pleistocene lithic evidence. However, it should be noted that direct association of human populations with the lake within the Mundafan Basin remains inferred, since the evidence for the latter was recovered from sediments deposited during more arid conditions. This is not surprising, given that people would not have inhabited the lake itself, and the continued existence of a substantial waterbody (at least seasonally) during the later part of the sequence is highly likely.

Mundafan Al-Buhayrah fills a critical gap in archaeological understanding, and articulates the African Middle Palaeolithic record with those of the Levant and India. The observation that hominin groups in these disparate regions were behaving in similar ways, inferred from their lithic technology, is consistent with a widespread dispersal of $H$. sapiens into southern Asia correlating with environmental amelioration across the Saharo-Arabian belt with the formation of rivers and lakes such as that at Mundafan. Given that this technology is also similar to that associated with $H$. sapiens in Africa by the late Middle Pleistocene, this dispersal into Asia does not seem to have occurred due to a technological or cognitively facilitated 'revolution'. The evidence from MDF-61 suggests that the MIS 5 Levantine occupation was probably not a localized failed dispersal, but part of a broad occupation of southern Asia by $H$. sapiens.

\section{Acknowledgements}

This study was funded by a European Research Council grant (295719), awarded to MDP. We thank H.R.H. Prince Sultan bin Salman bin Abdul Aziz, President of the Saudi Commission for Tourism and Antiquities (SCTA) and Prof. Ali al-Ghabban (VicePresident, SCTA) for permission to conduct this research. We thank Jamal Omar (then Head of the Research and Excavation Centre, SCTA) and Salih al-Morreah (Head of Najran Region Branch, SCTA) for facilitating this study at Mundafan. The Photographs in Fig. 8 were provided by Ian R. Cartwright, Institute of Archaeology, University of Oxford. Author contributions: HSG and TSW wrote the paper, with contributions from all authors; lithic analysis was undertaken by HSG, RC, CS and EMLS; OSL dating was undertaken by LCB; palaeoenvironmental analysis was undertaken by AP and AGP; palaeoecological analysis of non-marine molluscs and ostracods was undertaken by TSW; mapping and palaeohydrological reconstructions by RPJ and PB; study conceived and designed by MDP, AA, HSG and RC.

\section{Appendix A. Supplementary data}

Supplementary data related to this article can be found at http:// dx.doi.org/10.1016/j.quascirev.2015.04.020.

\section{References}

Adamiec, G., Aitken, M.J., 1998. Dose-rate conversion factos: update. Anc. TL 16, $37-50$.

Adamiec, G., Bailey, R.M., Wang, X.L., Wintle, A.G., 2008. The mechanism of thermally transferred optically stimulated luminescence in quartz. J. Phys. D Appl. Phys. 41, 135503.

Aitken, M.J., 1985. Thermoluminescence Dating. Academic Press, London.

Alonso-Zarza, A.M., 2003. Palaeoenvironmental significance of palustrine carbonates and calcretes in the geological record. Earth Sci. Rev. 60, 261-298.

Alonso-Zarza, A.M., Wright, V.P., 2010. Palustrine carbonates. Dev. Sedimentol. 61, 103-131.

Al Shuaibi, A.A., Khalaf, F.I., 2011. Development and lithogenesis of the palustrine and calcrete deposits of the Dibdibba alluvial fan, Kuwait. J. Asian Earth Sci. 42, $423-439$.

Aref, M.A.M., 2003. Classification and depostional environments of Quaternary pedogenic gypsum crusts (gypcrete) from east of the Fayum depression, Egypt. Sediment. Geol. 155, 87-108.

Armitage, S.J., Jasim, S.A., Marks, A.E., Parker, A.G., Usik, V.I., Uerpmann, H.-P., 2011. The southern route 'out of Africa': evidence for an early expansion of modern humans into Arabia. Science 331, 453-456.

Bailey, R.M., Arnold, L.J., 2006. Statistical modelling of single grain quartz De distributions and an assessment of procedures for estimating burial dose. Quat. Sci. Rev. 25, 2475-2502.

Ballarini, M., Wallinga, J., Wintle, A.G., Bos, A.J.J., 2007a. A modified SAR protocol for optical dating of individual grains from young quartz samples. Radiat. Meas. 42, 360-369.

Ballarini, M., Wallinga, J., Wintle, A.G., Bos, A.J.J., 2007b. Analysis of equivalent-dose distributions for single grains of quartz from modern deposits. Quat. Geochronol. 2, 77-82.

Bateman, M.D., Boulter, C.H., Carr, A.S., Frederick, C.D., Peter, D., Wilder, M., 2007a. Preserving the palaeoenvironmental record in drylands: bioturbation and its significance for luminescence-derived chronologies. Sediment. Geol. 195, 5-19.

Bateman, M.D., Boulter, C.H., Carr, A.S., Frederick, C.D., Peter, D., Wilder, M., 2007b. Detecting post-depositional sediment disturbance in sandy deposits using optical luminescence. Quat. Geochronol. 2, 57-64.

Boivin, N., Fuller, D.Q., Dennell, R., Allaby, R., Petraglia, M.D., 2013. Human dispersal across diverse environments of Asia during the Upper Pleistocene. Quat. Int. 300, 32-47.

Bøtter-Jensen, L., Bulur, E., Duller, G.A.T., Murray, A.S., 2000. Advances in luminescence instrument systems. Radiat. Meas. 32, 523-528.

Bøtter-Jensen, L., Andersen, C.E., Duller, G.A.T., Murray, A.S., 2003. Developments in radiation, simulation and obeservation facilities in luminescence measurements. Radiat. Meas. 37, 535-541.

Breeze, P.S., Drake, N.A., Groucutt, H.S., Parton, A., Jennings, R.P., White, T.S., ClarkBalzan, L., Shipton, C., Scerri, E.M.L., Stimpson, C.M., Crassard, R., Hilbert, Y., Alsharekh, A., Al-Omari, A., Petraglia, M.D., 2015. Remote sensing and GIS techniques for reconstructing Arabian palaeohydrology and identifying archaeological sites. Quat. Int. http://dx.doi.org/10.1016/j.quaint.2015.01.022.

Brennan, B.J., 2003. Beta doses to spherical grains. Radiat. Meas. 37, 299-303.

Burns, S.J., Fleitmann, D., Matter, A., Neff, U., Mangini, A., 2001. Speleothem evidence from Oman for continental pluvial events during peak interglacial periods. Geology 29, 623-626.

Clark, R.L. 1982. Point count estimation of charcoal in pollen preparations and thin sections of sediments. Pollen Spores 24, 523-535.

Clemens, S., Press, W.L., 2003. A 350,000 year summer-monsoon multi-proxy stack from the Owen Ridge, Northern Arabian Sea. Marine Geo. 201, 35-51.

Crassard, R., 2009. The Middle Palaeolithic of Arabia: the view from the Hadramawt region, Yemen. In: Petraglia, M.D., Rose, J.I. (Eds.), The Evolution of Human Populations in Arabia: Paleoenvironments, Prehistory and Genetics. Springer, Netherlands, pp. 151-168.

Crassard, R., Hilbert, Y.H., 2013. A Nubian complex site from central Arabia: implications for Levallois taxonomy and human dispersals during the Upper Pleistocene. PLoS ONE 8, e69221.

Crassard, R., Petraglia, M.D., Drake, N.A., Breeze, P., Gratuze, B., Alsharekh, A., Arbach, M., Groucutt, H.S., Khalidi, L., Michelsen, N., Robin, C.J., Schiettecatte, J., 2013. Middle Palaeolithic and Neolithic occupations around Mundafan Palaeolake, Saudi Arabia: implications for climate change and human dispersals. PLOS ONE 8, e69665.

Cunningham, A.C., DeVries, D.J., Schaart, D.R., 2012. Experimental and computational simulation of beta heterogeneity in sediment. Radiat. Meas. 47, 1060-1067.

Dearing, J., 1999. Magnetic susceptibility. In: Walden, J., Oldfield, F., Smith, J. (Eds.), Environmental Magnetism: a Practical Guide, Quaternary Research Association Technical Guide, vol. 6. Quaternary Research Association, London, pp. 35-63.

de Kock, K.N., Wolmarans, C.T., 2009. Distribution and habitats of Melanoides tuberculata (Müller, 1774) and M. victoriae (Dohrn, 1865) (Mollusc: Prosobranchia: Thiaridae) in South Africa. Water SA 35, 713-1420.

Delagnes, A., Tribolo, C., Bertran, P., Brenet, M., Crassard, R., Jaubert, J., Khalidi, L. Mercier, N., Nomade, S., Peigné, S., Sitzia, L., Tournepiche, J.-F., Al-Halibi, M., AlMosabi, A., Macchiarelli, R., 2012. Inland human settlement in southern Arabia 55,000 years ago. New evidence from the Wadi Surdud Middle Paleolithic site complex, western Yemen. J. Hum. Evol. 63, 452-474.

Delagnes, A., Crassard, R., Bertran, P., Sitzia, L., 2013. Cultural and human dynamics in southern Arabia at the end of the Middle Paleolithic. Quat. Int. 300, 234-243. 
Duller, G.A.T., 2003. Distinguishing quartz and feldspar in single grain luminescence measurements. Radiat. Meas. 37, 161-165.

Duller, G.A.T., 2012. Improving the accuracy and precision of equivalent doses determined using the optically stimulated luminescence signal from single grains of quartz. Radiat. Meas. 47, 770-777.

Dundee, D.S., Paine, A., 1977. Ecology of the snail Melanoides tuberculata (Müller), intermediate host of the human liver fluke (Opisthorchis sinensis) in New Orleans, Louisiana. Naut. 91, 17-20.

Duval, M., Arnold, L.J., 2013. Field gamma dose-rate assessment in natural sedimentary contexts using $\mathrm{LaBr} 3(\mathrm{Ce})$ and $\mathrm{NaI}(\mathrm{Tl})$ probes: a comparison between 'threshold' and 'windows' techniques. Appl. Radiat. Isotopes 74, 36-45.

Fleitmann, D., Matter, A., 2009. The speleothem record of climate variability in southern Arabia. Comptes Rendus Geosci. 341, 633-642.

Fleitmann, D., Burns, S.J., Neff, U., Mangini, A., Matter, A., 2003. Changing moisture sources over the last 330,000 years in northern Oman from fluid-inclusion evidence in speleothems. Quat. Res. 60, 223-232.

Fleitmann, D., Burns, S.J., Pekala, M., Mangini, A., Al-Subbary, A., Al-Aowah, M., Kramers, J., Matter, A., 2011. Holocene and Pleistocene pluvial periods in Yemen, southern Arabia. Quat. Sci. Rev. 30, 783-787.

Galbraith, R., Roberts, R., Laslett, G., Yoshida, H., Olley, J., 1999. Optical dating of single and multiple grains of quartz from Jinmium rock shelter, northern Australia: part I, experimental design and statistical models. Archaeometry 41, 339-364.

Guérin, G., Mercier, N., Nathan, R., Adamiec, G., Lefrais, Y., 2012. On the use of the infinite matrix assumption and associated concepts: a critical review. Radiat. Meas. 47, 778-785.

Groucutt, H.S., 2014. Middle Palaeolithic point technology, with a focus on the site of Tor Faraj (Jordan, MIS 3). Quat. Int. 350, 205-226.

Groucutt, H.S., Petraglia, M.D., 2012. The prehistory of the Arabian Peninsula: deserts, dispersals and demography. Evol. Anthropol. 21, 113-125.

Groucutt, H.S., Blinkhorn, J., 2013. The Middle Palaeolithic in the desert and its implications for understanding hominin adaptation and dispersal. Quat. Int. $300,1-12$.

Groucutt, H.S., Petraglia, M.D., 2014. An Arabian perspective in the dispersal of Homo sapiens out of Africa. In: Dennell, R., Porr, M. (Eds.), Southern Asia, Australia and Human Origins. Cambridge University Press, Cambridge, pp. $51-63$.

Groucutt, H.S., Shipton, C., Alsharekh, A., Jennings, R., Scerri, E.M.L., Petraglia, M.D., 2015a. Late Pleistoene lakeshore settlement in northern Arabia: Middle Palaeolithic technology from Jebel Katefeh, Jubbah. Quat. Int. http://dx.doi.org/ 10.1016/j.quaint.2014.12.001.

Groucutt, H.S., Scerri, E.M.L., Lewis, L., Clark-Balzan, L., Blinkhorn, J., Jennings, R.P., Parton, A., Petraglia, M.D., 2015b. Stone tool assemblages and models for the dispersal of Homo sapiens out of Africa. Quat. Int. http://dx.doi.org/10.1016/ j.quaint.2015.01.039.

Haslam, M., Clarkson, C., Roberts, R.G., Bora, J., Korisettar, R., Ditchfield, P., Chivas, A.R., Harris, C., Smith, V., Oh, A., Eksambekar, S., Boivin, N., Petraglia, M., 2012. A southern Indian Middle Palaeolithic occupation surface sealed by the 74 ka Toba eruption: further evidence from Jwalapuram locality 22. Quat. Int. 258, $148-164$.

Heiri, O., Lotter, A.F., Lemcke, G., 2001. Loss on ignition as a method for estimating organic and carbonate content in sediments: reproducibility and comparability of results. J. Paleolimnol. 25, 101-110.

Hovers, E., 2009. The Lithic Assemblages of Qafzeh Cave. Oxford University Press, Oxford.

Jacobs, Z., Duller, G.A.T., Wintle, A.G., 2003. Optical dating of dune sand from Blombos Cave, South Africa: II - single grain data. J. Hum. Evol. 44, 613-625.

Jacobs, Z., Wintle, A.G., Roberts, R.G., Duller, G.A.T., 2008. Equivalent dose distributions from single grains of quartz at Sibudu, South Africa: context, causes and consequences for optical dating of archaeological deposits. J. Archaeol. Sci. 35, $1808-1820$

Jennings, R.P., Singarayer, J., Stone, E.J., Krebs-Kanzow, U., Khon, V., Nisancioglu, K.H., Pfeiffer, M., Zhang, X., Parker, A., Parton, A., Groucutt, H.S., White, T.S., Drake, N.A., Petaglia, M.D., 2015. The greening of Arabia: multiple opportunities for human occupation of the Arabian Peninsula during the Late Pleistocene inferred from an ensemble of climate model simulations. Quat. Int. http://dx.doi.org/10.1016/j.quaint.2015.01.006.

Kalchgruber, R., Fuchs, M., Murray, A.S., Wagner, G.A., 2003. Evaluating dose-rate distributions in natural sediments using $\alpha-\mathrm{Al}_{2} \mathrm{O}_{3}: \mathrm{C}$ grains. Radiat. Meas. 37, 293-297.

Kobusiewicz, M., 1999. Excavations at Sinai-20, the Split rock site, Zarnoq Locality. In: Eddy, F.W., Wendorf, F., associates (Eds.), An Archaeological Investigation of the Central Sinai, Egypt. University Press of Colorado, Boulder, Colorado, pp. 193-207.

Kobusiewicz, M., Schild, R., Bluszcz, A., Wendorf, F., 2001. Reassessing chronostratigraphic position of the Split rock site, Sinai. In: Gehlen, B., Heinen, M. Tillmann, A. (Eds.), Zeit-Raüme, Gedenkschrift für Wolfgang Taute. Deutsche Gesellscaft für und Frühgeschichte, Bonn, pp. 227-236.

Leuschner, D.C. Sirocko, F. 2003. Orbital insolation forcing of the Indian Monsoon a motor for global climate changes? Palaeogeogr. Palaeoclimatol. Palaeoecol. 197, 83-95.

Lomax, J., Hilgers, A., Twidale, C.R., Bourne, J.A., Radtke, U., 2007. Treatment of broad palaeodose distributions in OSL dating of dune sands from the western Murray Basin, South Australia. Quat. Geochronol. 2, 51-56.
Mayya, Y.S., Morthekai, P., Murari, M.K., Singhvi, A.K., 2006. Towards quantifying beta microdosimetric effects in single-grain quartz dose distribution. Radiat. Meas. 41, 1032-1039.

McClure, H.A., 1976. Radiocarbon chronology of late Quaternary lakes in the Arabian Desert. Nature 263, 755-756.

McClure, H.A., 1984. (unpublished Ph.D. thesis), University College London.

McDougall, I., Brown, F.H., Fleagle, J.G., 2005. Stratigraphic placement and age of modern humans from Kibish, Ethiopia. Nature 433, 733-736.

Meisch, C., 2000. Freshwater Ostracoda of Western and Central Europe. In: Süßwasserfauna von Mitteleuropa, vol. 8/3. Gustav Fischer, Stuttgart.

Mellars, P., Cori, K.C., Carr, M., Soares, P.A., Richards, M.B., 2013. Genetic and archaeological perspectives on the initial modern human colonization of southern Asia. Proc. Natl. Acad. Sci. U. S. A. 110, 10699-10704.

Mercier, N., Falguères, C., 2007. Field gamma dose-rate measurement with a NaI(Tl) detector: re-evaluation of the 'threshold' technique. Anc. TL 25, 1-4.

Murray, A.S., Roberts, R.G., 1998. Measurement of the equivalent dose in quartz using a regenerative-dose single-aliquot protocol. Radiat. Meas. 29, 503-515.

Murray, A.S., Wintle, A.G., 2000. Luminescence dating of quartz using and improved single-aliquot regenerative-dose protocol. Radiat. Meas. 32, 57-73.

Nathan, R.P., Thomas, P.J., Jain, M., Murray, A.S., Rhodes, E.J., 2003. Environmental dose rate heterogeneity of beta radiation and its implications for luminescence dating: Monte Carlo modelling and experimental validation. Radiat. Meas. 37 305-313.

Neubert, E., 1998. Annotated checklist of the terrestrial and freshwater molluscs of the Arabian Peninsula with descriptions of new species. Fauna Arabia 17, 333-461.

Nishiaki, Y., Kanjo, Y., Muhesen, S., Akazawa, T., 2012. The temporal variability of Late Levantine Mousterian lithic assemblages from Dederiyeh Cave, Syria. Eurasian Prehistory 9, 3-27.

Olley, J.M., Caitcheon, G.G., Roberts, R.G., 1999. The origin of dose distributions in fluvial sediments, and the prospect of dating single grains from fluvial deposits using optically stimulated luminescence. Radiat. Meas. 30, 207-217.

Parton, A., Parker, A.G., Farrant, A.R., Leng, M.J., Telfer, M.W., Breeze, P., Groucutt, H.S., Petraglia, M.D., 2015a. Alluvial fan records from southeast Arabia reveal multiple windows for human dispersal. Geology 43, 295-298.

Parton, A., White, T.S., Parker, A.G., Breeze, P.S., Jennings, R., Groucutt, H.S., Petraglia, M.D. 2015b. Orbital-scale climate variability in Arabia as a potential motor for human dispersals. Quat. Int. http://dx.doi.org/10.1016/j.quaint.2015.01.005.

Parker, A.G., Lee-Thorp, J., Mitchell, P., 2011. Late Holocene neoglacial conditions from the Lesotho highlands, southern Africa: phytolith and stable carbon isotope evidence from the archaeological site of Likoaeng. Proc. Geol. Assoc. 122, 201-211.

Petraglia, M.D., Rose, J.I., 2009. The Evolution of Human Populations in Arabia: Paleoenvironments, Prehistory and Genetics. Springer, Netherlands.

Petraglia, M.D., Korisettar, R., Boivin, N., Clarkson, C., Ditchfield, P., Jones, S., Koshy, J., Lahr, M.M., Oppenheimer, C., Pyle, D., Roberts, R., Schwenninger, J.-L., Arnold, L., White, K., 2007. Middle Paleolithic assemblages from the Indian subcontinent before and after the Toba super-eruption. Science 317, 114-116.

Petraglia, M.D., Haslam, M., Fuller, D.Q., Boivin, N., Clarkson, C., 2010. Out of Africa: new hypotheses and evidence for the dispersal of Homo sapiens along the Indian Ocean rim. Ann. Hum. Biol. 37, 288-311.

Petraglia, M.D., Alsharekh, A.M., Crassard, R., Drake, N.A., Groucutt, H. Parker, A.G., Roberts, R.G., 2011. Middle Palaeolithic occupation on a Marine Isotope Stage 5 lakeshore in the Nefud desert, Saudi Arabia. Quat. Sci. Rev. 30, 1555-1559.

Petraglia, M.D., Alsharekh, A., Breeze, P., Clarkson, C., Crassard, R., Drake, N.A., Groucutt, H.S., Jennings, R., Parker, A.G., Parton, A., Roberts, R.G., Shipton, C. Matheson, C., al-Omari, A., Veall, M.-A., 2012. Hominin dispersal into the Nefud desert and Middle Paaeolithic settlement along the Jubbah Palaeolake, Northern Arabia. PLoS ONE 7 (11), e49840. http://dx.doi.org/10.1371/ journal.pone.0049840.

Porat, N., Dullet, G.A.T., Roberts, H.M., Wintle, A.G., 2009. A simplified SAR protocol for TT-OSL. Radiat. Meas. 44, 538-542.

Prescott, J.R., Stephan, L.G., 1982. The contribution of cosmic radiation to the environmental dose for thermoluminescent dating: latitude, altitude and depth dependences. PACT 6, 17-25.

Prescott, J.R., Hutton, J.T., 1988. Cosmic ray and gamma ray dosimetry for TL and ESR. Nucl. Tracks Radiat. Meas. 14, 223-227.

Prescott, J.R., Hutton, J.T., 1994. Cosmic ray distributions and ESR dating: large depths and long-term time variations. Radiat. Meas. 23, 497-500.

Rhodes, E.J., Schwenninger, J.-L., 2007. Dose rates and radioisotope concentrations in the concrete calibration blocks at Oxford. Anc. TL 25,5-8.

Rink, W.J., Dunbar, J.S., Tschinkel, W.R., Kwapich, C., Repp, A., Stanton, W., Thulman, D.K., 2013. Subterranean transport and deposition of quartz by ants in sandy sites relevant to age overestimation in optical luminescence dating. J. Archaeol. Sci. 40, 2217-2226.

Rose, J.I., 2010. New light on human prehistory in the Arabo-Persian Gulf Oasis. Curr Anthropol. 51, 849-883.

Rose, J.I., Usik, V.I., Marks, A.E., Hilbert, Y.H., Galletti, C.S., Parton, A., Geiling, J.M., Černý, V., Morley, M.W., Roberts, R.G., 2011. The Nubian complex of Dhofar Oman: an African middle stone age industry in southern Arabia. PLoS ONE 6, e28239.

Rosenberg, T.M., Preusser, F., Fleitmann, D., Schwalb, A., Penkman, K. Schmid, T.W., Al-Shanti, M.A., Kadi, K., Matter, A., 2011a. Humid periods in 
southern Arabia: windows of opportunity for modern human dispersal. Geology 39, 1115-1118.

Rosenberg, T.M., Preusser, F., Wintle, A.G., 2011b. A comparison of single and multiple aliquot TT-OSL data sets for sand-sized quartz from the Arabian Peninsula. Radiat. Meas. 46, 573-579.

Scally, A., Durbin, R., 2012. Revising the human mutation rate: implications for understanding human evolution. Nat. Rev. Genet. 13, 745-753.

Scerri, E.M., Groucutt, H.S., Jennings, R.P., Petraglia, M.D., 2014a. Unexpected technological heterogeneity in northern Arabia indicates complex Late Pleistocene demography at the gateway to Asia. J. Hum. Evol. 75, 125-142.

Scerri, E.M.L., Drake, N.A., Jennings, R.P., Groucutt, H.S., 2014b. Earliest evidence for the structure of Homo sapiens populations in Africa. Quat. Sci. Rev. 101, 207-216.

Scerri, E.M.L., Breeze, P.S., Parton, A., Groucutt, H.S., White, T.S., Stimpson, C., ClarkBalzan, L., Jennings, R., Alsharekh, A., Petraglia, M.D., 2015. Middle to Late Pleistocene human habitation in the western Nefud desert, Saudi Arabia. Quat. Int. http://dx.doi.org/10.1016/j.quaint.2014.09.036.

Shea, J.J., 2008. The Middle Stone Age archaeology of the Lower Omo Valley Kibish Formation: excavations, lithic assemblages, and inferred patterns of early Homo sapiens behavior. J. Hum. Evol. 55, 448-485.

Shea, J.J., 2013. Stone Tools in the Palaeolithic and Neolithic Near East: a Guide. Cambridge University Press, Cambridge.

Stringer, C., 2011. The Origin of Our Species. Penguin, UK.
Usik, V.I., Rose, J.I., Hilbert, Y.H., Van Peer, P., Marks, A.E., 2013. Nubian Complex reduction strategies in Dhofar, southern Oman. Quat. Int. 300, 244-266.

Vaks, A., Bar-Matthews, M., Ayalon, A., Matthews, A., Halicz, L., Frumkin, A., 2007. Desert speleothems reveal climatic window for African exodus of early modern humans. Geology 35, 831-834.

van Harten, D., 2000. Variable noding in Cyprideis torosa (Ostracoda, Crustacea): an overview, experimental results and a model from Catastrophe Theory. Hydrobiologia 419, 131-139.

Wendorf, F., Close, A.E., Schild, R., associates (Eds.), 1993. Egypt during the Last Interglacial: the Middle Paleolithic of Bir Tarfawi and Bir Sahara East. Plenum Press, New York.

Wintle, A.G., Murray, A.S., 2006. A review of quartz optically stimulated luminescence characteristics and their relevance in single-aliquot regeneration dating protocols. Radiat. Meas. 41, 369-391.

Yellen, J., Brooks, A., Helgren, D., Tappen, M., Ambrose, S., Bonnefille, R., Feathers, J., Goodfriend, G., Ludwig, K., Renne, P., Stewart, K., 2005. The archaeology of Aduma Middle Stone age sites in the Awash Valley, Ethiopia. Paleoanthropology 2005, 25-100.

Yoshida, H., Roberts, R.G., Olley, J.M., Laslett, G.M., Galbraith, R.F., 2000. Extending the age range of optical dating using single 'supergrains' of quartz. Radiat. Meas. $32,439-446$. 